UCRL-534S6

Distribution Categary UC-70

\title{
DSCLATMIR
}

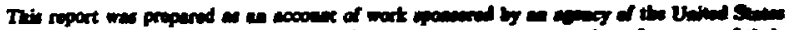

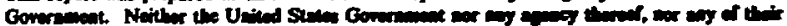

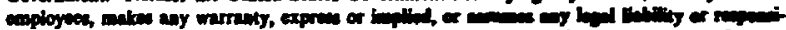

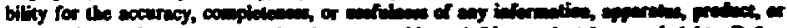

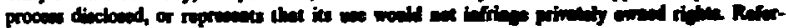

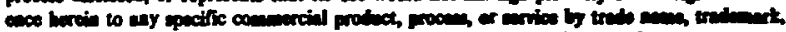

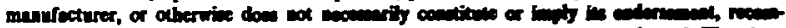

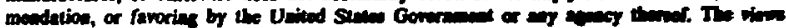

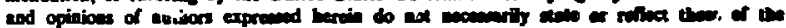
United States Gomarameat or any sceacy thuer.

\section{Heater Test 1, Climax Stock Granite, Nevada}

\author{
D. N. Montan and W. E. Bradkin
}

Manuscript Date: October 1984

UCRL- -53496

DE85 014847 


\section{Contents}

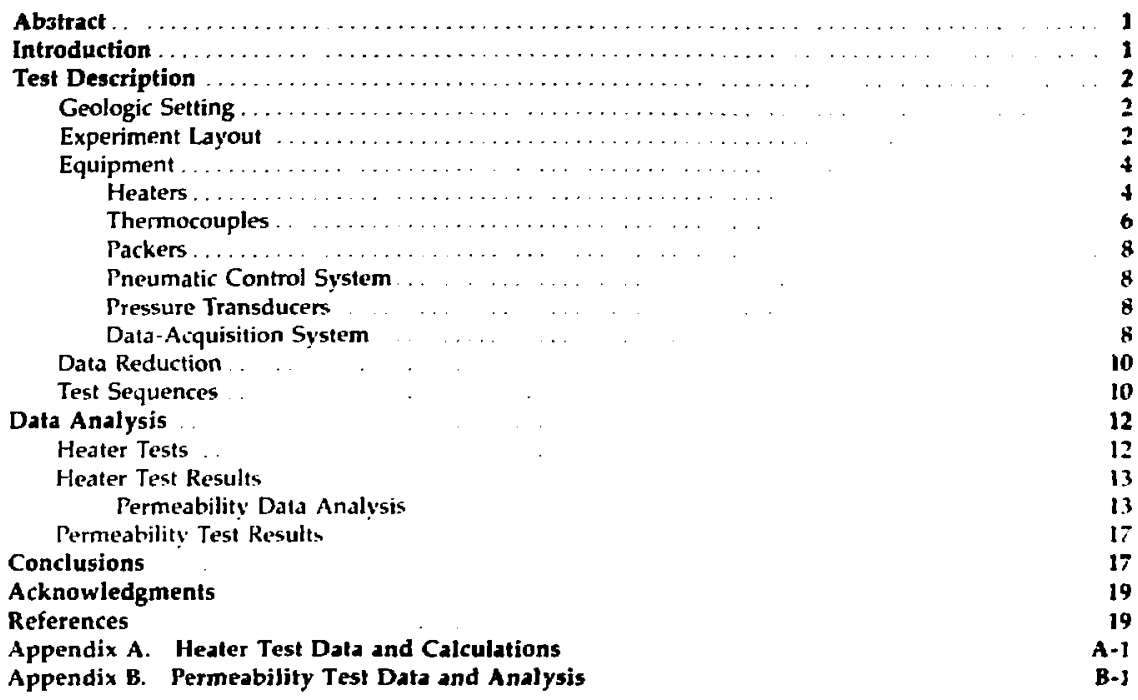




\title{
Heater Test 1, \\ Climax Stock Granite, Nevada
}

\begin{abstract}
We conducted a series of in-situ tests in the Climax Stuck. an intrusise granite formation at the Nevada Test Site, to validate the concept of housing a nuclear vaste repository in granitic crystalline rock. The thermal propertics of the granite were medsured with resistante heaters and thermocouple frames that had been emplaced in drilled holes in the floor of a drift $\mathbf{4 2 0} \mathrm{m}$ below the surface. Data analysis was performed primariiy by comparing the measured and calculated temperature histuries, varying conn. ductivity and diffusivity in the calculations until reasonable agreement was achieved The best-fit value for in-situ conductivity was approximately. $3.1 \mathrm{~W} / \mathrm{m} \cdot K$. and the de duced value for in-situ diffusivity was approximately $1.2 \mathrm{~mm}^{2} / \mathrm{s}$. Anisotropic effects in the thermal field were less than $10 \%$.

Permeability was determined by sealing off portions of the drilleat holes. using in. flatable rubber packers and an air-pressurization system. We then compared the resulting decay in pressure with analytic solutions of the pressure luss from a cylindnial surerce in an infinite isotropic medium, obtaining a permeability of approsimateiy I nanedarcy (nD) at about $30^{\circ} \mathrm{C}$. As the temperature increased, the permesbility decreased to about (0.2 $\mathrm{nD}$ at about $50^{\circ} \mathrm{C}$ and became tor small to measure (- $0.02 \mathrm{ni}$ ) at hagher temperatures.

These tests provided new data on the in-situ properties of a granite trpeal of the Basin and Range province and significantly advanced our understanding of and abtity to perform in-situ thermal and permeahility measurements. The knowledge will be if an siderable alue for future spent-fuel tests.
\end{abstract}

\section{Introduction}

Lawrence Livermore National Laboratory (LLNL) has conducted a series of in-situ tests in the Climax Stock, an intrusive granite formation at the Nevada Test Site. These tests are intended to validate the concept of housing a nuclear waste respository in granitic crystalline rock. The heater test series, which is part of this series of validation tests, was designed to obtain basic technical information on the in-situ thermal conductivity. thermal diffusivity, and permeability of a granite typical of those found in the Basin and Range Province.

The first two tests in the heater series, performed during October 1977 to February 1978. were designed to obtain representative values for the thermal conductivity and deffusives of a gran ite under in-situ conditions. They were alno de signed to determine how dependent thes' proper ties were on the principal fracture directuon Both tests centered around electrical heater elements that had been empiaced in a ho' heneath the floor of the experiment area. a drift $\$ 20 \mathrm{~m}$ below the ground surface. An array of thermocouples monitored the temperature history at various distances from thim emplaced heat sources. Thennal conductivity and diffusivity were determined from the resulting temperature histories and known heat sources.

The third test, performed duriang A pril to July 1978, was designed to determine the in-situ 
permeability of the medium as a function of temperature. This was done by "packing off" crilled holes in the granite, pressurizing them with air, and monitoring the subsequent pressure decay. This technique and the test hardware were sensitive enough to Jetermine permeabilities as low as $0.02 \mathrm{nD}$.

Although this report documents the results of tests conducted several years agc, the results are made available for two reasons: First, the thermal properties data were used in the design of the Spent Fuel Test-Climax': hence, their source must be available for reference. Second. the permeability values and the analytical methous used to detemine those vaiues are not available elsewhere. They are experted to become increasingly important now that crystalline rocks are again being considered for a permanent nuclear waste repository. For related test information. see Refs. 2 to 5.

\section{Test Description}

\section{Geologic Setting}

The Climax Stock is a composite granitic intrusive body iocated near the northeast comer of the Nevada Test Site, about $100 \mathrm{~km}$ northwest of Las Vegas. It is named for the Climax tungsten mine, located in Paleozoic rucks north of the granitic outcrop. The Stock, which outcrops over an area of ahout $4 \mathrm{~km}^{*}$, has heen explored extensively in support of past nuclear test activities. Geophysical evidence suggests that the Stock ex. pands conically to an area of about $100 \mathrm{~km}^{2}$ at a depth of several kilometers.

The granitic Stock is composed of two main units-granodiorite (to the north) and quartz inonzonite (to the south)-that contain varying propertions of the same minerals. Both units have a grain size of about 1 to $4 \mathrm{~mm}$, but the quartz monzonite, which is richer in feldspar, contains scattered large feldspar crystals ranging up to $\mathbf{5 0}$ $\mathrm{mm}$ in length. The heater tests were conducted in the quarl $\angle$ monzonite unit. The test level $(420 \mathrm{~m}$ depth) is apprarently above the water table, and the granite appears to be unsaturated. However. about 1 to $2 w t \%$ water is localized in fractures and pores and should be free to migrate under thermal or pressire gradients.

The in-situ stress :nvironment near the test atea was measured using the overcoring technique. The least principal stress was $2.75 \mathrm{MPa}$ oriented $\mathrm{N} 42^{\circ} \mathrm{W} /-14^{\circ}$ and the maximum principal siress was $11.56 \mathrm{MPa}$ oriented N56 $6^{\circ}$ / $-29^{\circ}$." These measurements also indicated that significant variations in stress (as a result of the excavated drifts) extended about $1 \mathrm{~m}$ into the rock.
The ambient roxk temperature at experiment depth was $23^{\circ} \mathrm{C}$

\section{Experiment Layout}

The experimental sile is ne:ar the bottom of a $+25-m \cdot d e e p$ shaft $(2$ by $+m$ in crow section) that was constructed more than 15 years ago in sup" port of two nuclear weapon- effects tests. The firt nuclear detonation in the Climax Stork was the 5 ke Hardhat event (February 1962). with the detonation point $286 \mathrm{~m}$ below the surface arid about $245 \mathrm{~m}$ from the shaft. The seconet was the 6l-kt Piledriver e'vent (June 1966). at a depeth of $463 \mathrm{~m}$ and ahout $430 \mathrm{~m}$ from the shatt

The healer lesto were condested beneath the foor of an existing drift that was about $3 \mathrm{~m}$ wide and a 3-by-t-m alcove that wa excavated for the tests. An array of 17 imall diameter belec was drilled into the floor, using diamond core bics and water as a circulating medium. Of these', 13 were AX $(48 . \mathrm{mm}$-diam) holes for thermocouple em. piacement, two were $N \times$ (76-mm-dam) holes for a U.S. Geological Survey (USGS) add-en experiment, and two were NX/AX stepped holes for the heaters. This array, shown in Figs. 1 and 2 and described in Table 1 , is in an orthogonal pattern that is oriented approximately parallel and perpendicular to the major fracture sistem in the im. mediate vicinits: The $t w$ heater holes w'ere near the ends of the arrav, with the thermocouple holes at horizontal ranges of approximately 0.2 to $5 \mathrm{~m}$. from the heaters. The $5-\mathrm{m}$ hole was at the 


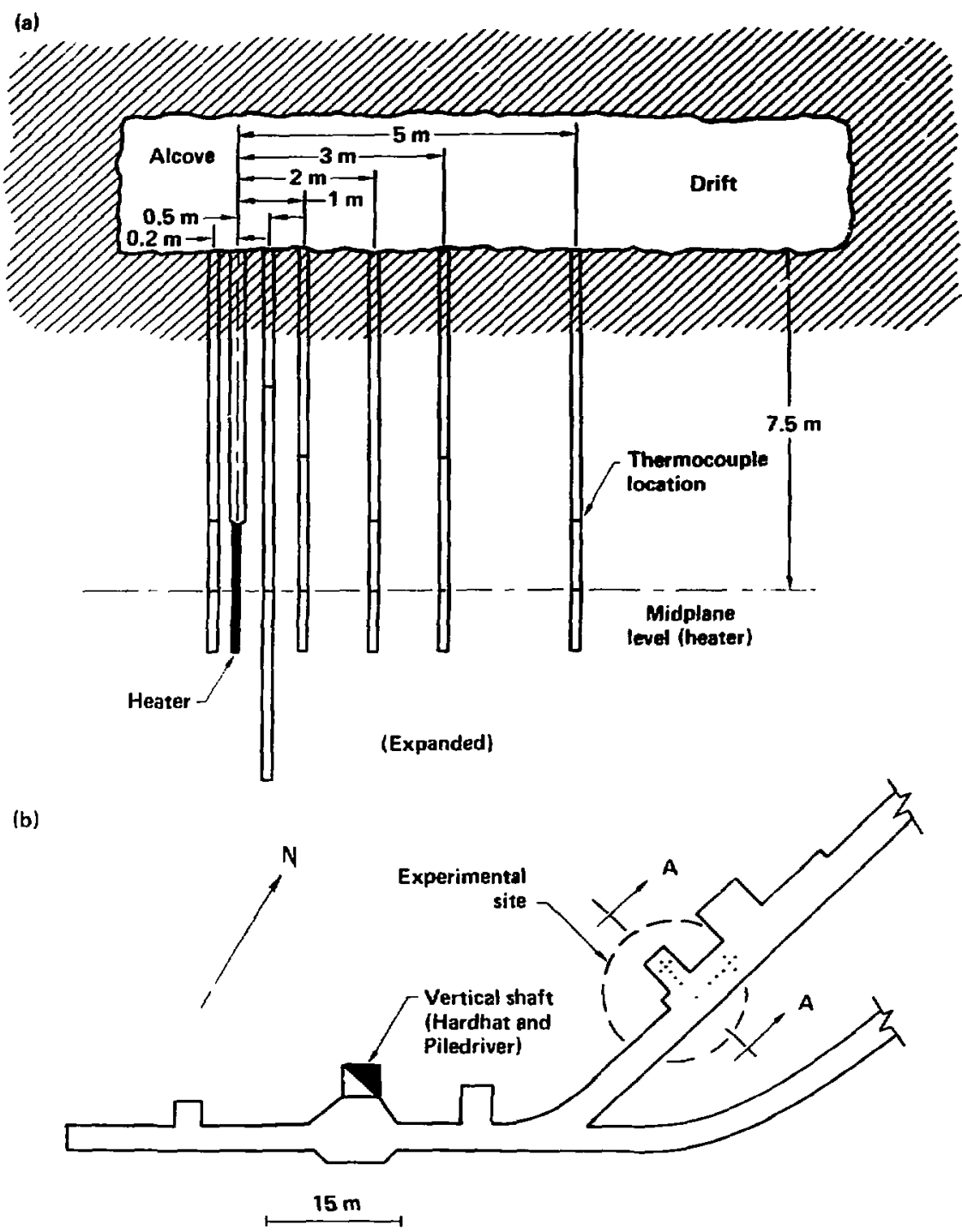

Figure 1. (a) Vertical cross section and (b) plot plan. 


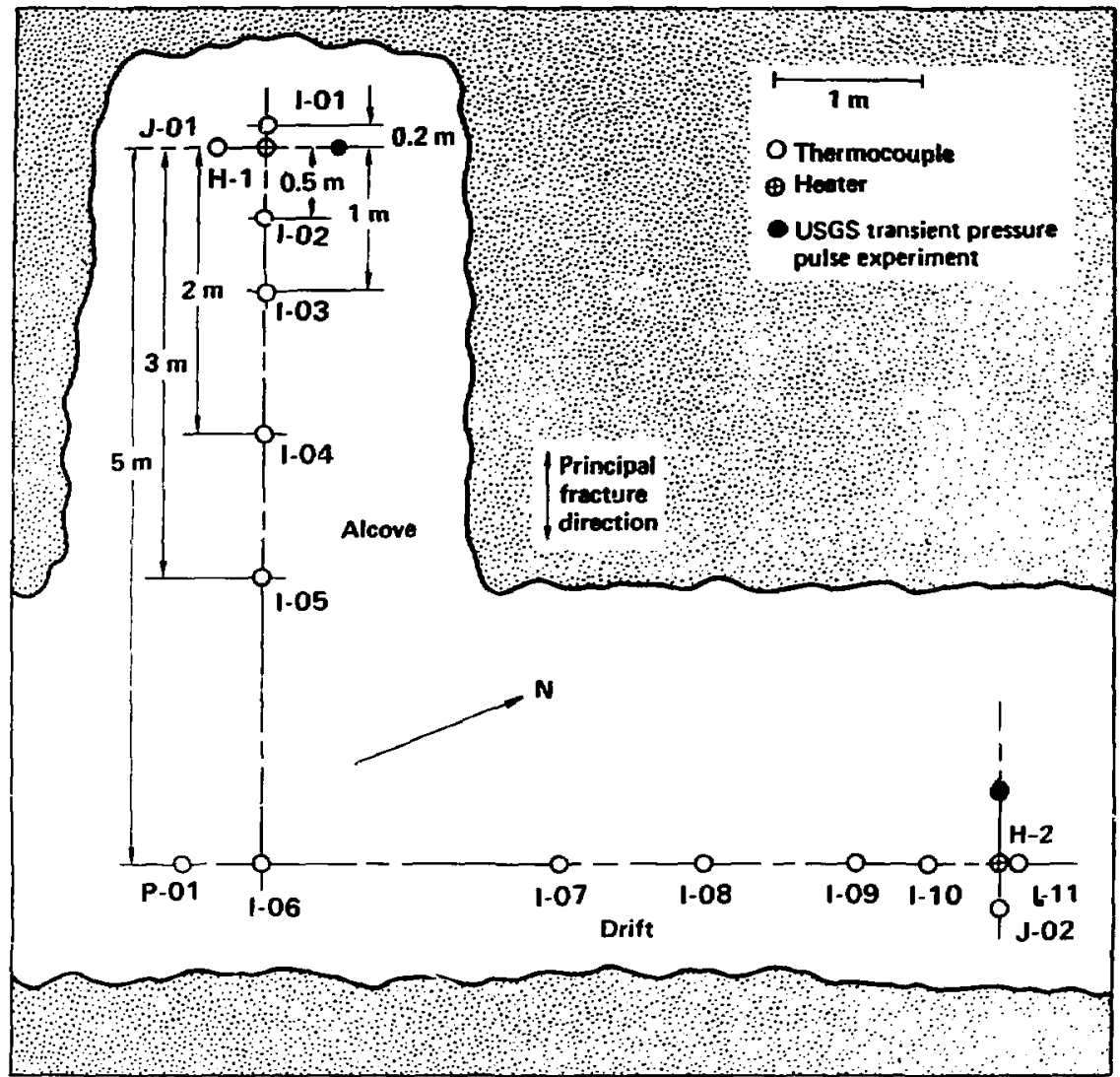

Figure 2. Heater test layout.

intersection of the two urthogortal lines of the arrat. The holes ivere all $9 \mathrm{~m}$ deep except for two which were $12 \mathrm{~m}$ deep. The heater midplane was at a depth of $7.5 \mathrm{~m}$.

All of the holes were surveyed optically with depth, using a movable light-source arget. Thus, -he as-built location of the thermocouples with respect to the heaters is known.

\section{Equipment}

All control and data-acquisition was normally handled in a trailer on the surface because of the expense (about $\$ 1000$ per day) involved in maintaining personnel access to the underground area and the expected duration of the experiment. Appropriate multiconductor shielded cables were run from the surface to the underground area by means of a 6-in.-diam conduit in the access shaft.

\section{Heaters}

The cartridge-type resistance heaters were rated for $5.28 \mathrm{~kW}$ at $240 \mathrm{~V}$ and had an active heating length of $2.9 \mathrm{~m}$. For the first test $(\mathrm{H}-1)$, the active elements were encased in a inconel sheath that was slightly longer than the $2.9-\mathrm{m}$ active 
length. The heater sheath was suspended at the NX/AX step by a $64-\mathrm{mm}$-diam flange and hung freely with a 38 -mm-diam disk at the bottom.

Table 1. Horizontal ranges of test array.

\begin{tabular}{|c|c|c|}
\hline Hole & $\begin{array}{c}\text { Nominal range } \\
\text { from heater } \\
\text { (m) }\end{array}$ & $\begin{array}{l}\text { As-broill range } \\
\text { from heater at } \\
\text { midplane (m) }\end{array}$ \\
\hline \multicolumn{3}{|l|}{$\mathrm{H} \cdot \mathrm{I}$} \\
\hline $\mid-0]$ & 0.2 & 0.285 \\
\hline 1.02 & 05 & 0.499 \\
\hline $1-03$ & 1.0 & 11.35 \\
\hline 1.114 & 2.0 & 2.005 \\
\hline 105 & 30 & 2821 \\
\hline 106 & 5.0 & 5.053 \\
\hline 1.01 & 0.3 & 0407 \\
\hline \multicolumn{3}{|l|}{$\mathrm{H}_{2}$} \\
\hline 1.16 & 50 & 4.920 \\
\hline $\mathrm{F} \cdot(1)^{-}$ & 30 & 2084 \\
\hline $1 \cdot 1.5$ & 20 & 1792 \\
\hline J.119 & 10 & 0.7 .15 \\
\hline $1-10$ & 05 & 0,369 \\
\hline [-1] & 02 & 0.399 \\
\hline $1-102$ & 0.3 & 0405 \\
\hline$\Gamma \cdot 01$ & 53 & 5.23 \\
\hline
\end{tabular}

I wo pins through a ceramic plug at the top of the sheath provided for electrical connections. The second heater was identical except that the sheath was $19 \mathrm{~mm}$ in diameter.

Initially, the heaters were emplaced using a tubing string that was then disengaged and removed from the holes. A later modification (developed after a short circuit) brought the power leads from the heater to the drift floor inside a permanent string of aluminum tubing with swaged fittings. The tubing isolated the power leads and connections from the water that refuxed above the heater. A short length of mineral wool insulation was wrapped around the tubing above the heater. and the rest of the hole was hackfilled with loose Perlite insulation. Figure 3 shows the heater assembly and the three thermocouples banded to it. The thermocouples, located near the top. bottom, and midpoint of the active part of the heater, were used to verify that the heater was operating and not at an excessive temperature.

The power level to each heater was set by a silicon-controlled rectifier $(S \Gamma R)$ controller that
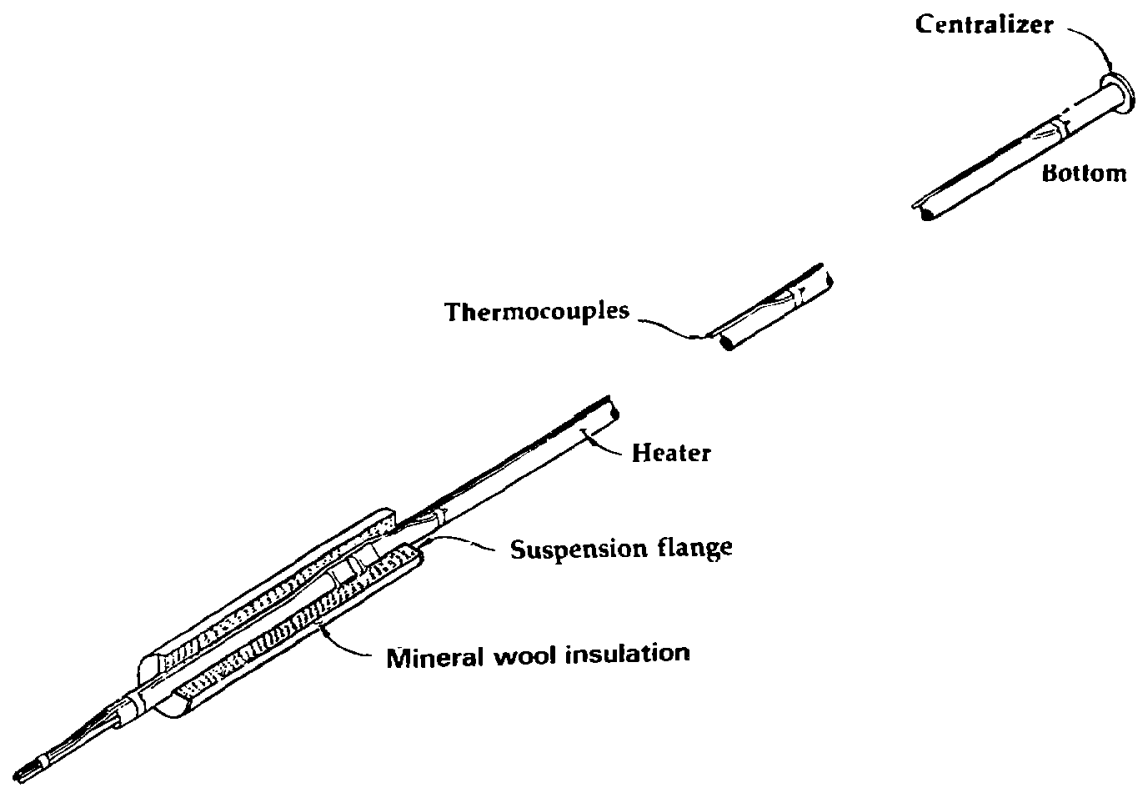

Figure 3. Heater assembly. 
previded a 0 to $100 \%$ variable duty cycle. The power levels could be set locally at the controllers in the drift and remotely at the surface station. The actual rower level of the heaters was monitored with power transducers that provided a direct-current (dc) voltage proportiona! to the power output of the controller. This voltage, along with the thermocouple voltage, was recorded by the data-acquisition system at the surface.

An identical heater, suspended from a packer on a stainless steel tubing gooseneck, was used for the permeability tests. The bottom centralizing disk was replaced by a spring centralizer, providing for easier emplacement and retrieval (Fig. 4).

\section{Thermocouples}

The thermocouples used were Type $K$ (Chromel-Alumel), 28-gauge wire, in 100-ft lengths, with 1/16-in. Inconel 600 metal sheaths and magnesium oxide insulation. The hot junctions were ungrounded. We chose Type $K$ thermocouples hecause they were suitable for our expected temperature range and because of the relatively high Seebeck coefficient. The sheaths, which were oxidation-resistant, were chosen to minimize or prevent damege to the thermocouple wires and junctions and appear to have been successful.

In addition to the six thermocouples on the heaters (three on each heater). we emplaced four thermocouples in each of the 13 instrumentalion holes. The emplacement technique was designed with three objectives in mind: accuracy of location, contact with the rock, and removability (for replacement if necessary and for future use of the holes). A typical 3-m-long thermocouple assembly is shown in Fig. 5. We used similar assemblies for the two holes in which the thermocouple measurements spanned more than $3 \mathrm{~m}$; in both cases, however, the vertical clearance in the drift required that the assemblies be made up of modules of $3 \mathrm{~m}$ or less.

The hot junctions of the thermocouples were silver soldered to 6-mm-diam copper pins that protruded through ceramic collars in the frame. The assemblies were then emplaced by a two-slep process. First, we lowered the frame into position, with the pins retracted and perpendicular to the dinection of the heater. Then. the lowering tube string was disengaged at a l-slot fixture and removed. In the second step. we inserted a "spear" of 13-mm-diam stainiess steel tubing down the

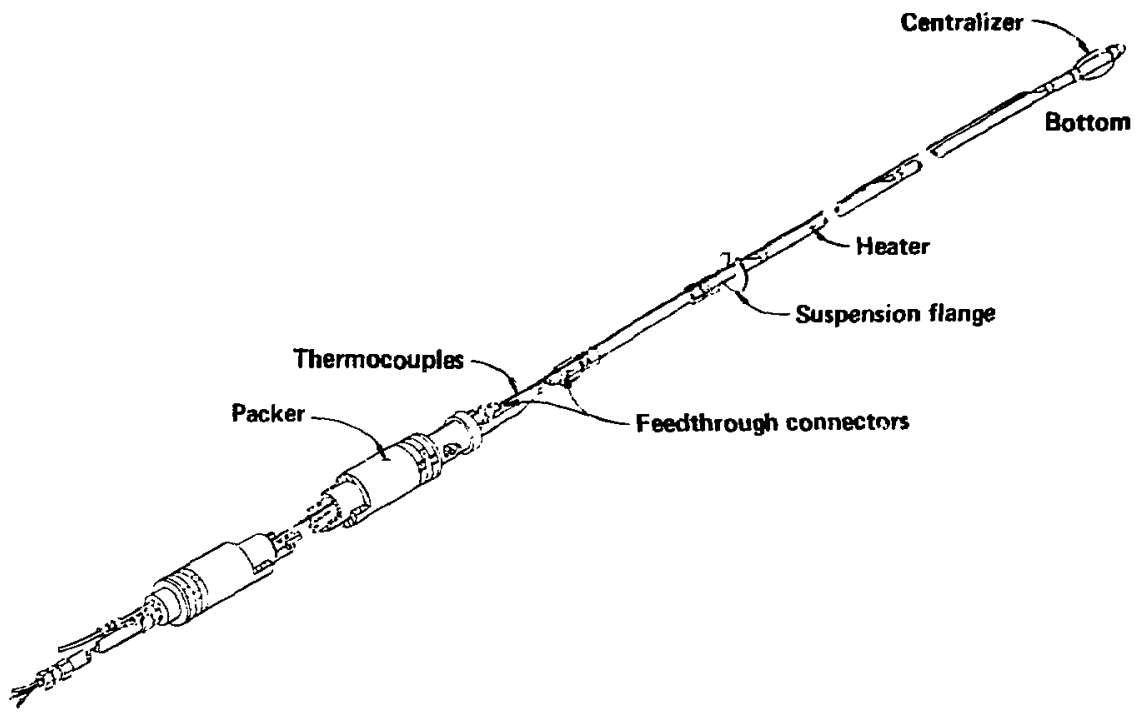

Figure 4. Heater packer assembly. 


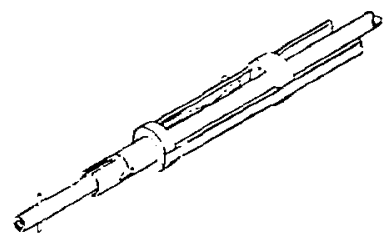

Figure 5. Thermacouple assembly.

central axis of the frame, activating the springs and driving the copper pins firmly against the rock. Aguin a J-slot fixture was u.ed to disengage the spear. The holes were backfilled with loose Perlite insulation.

For the permeability tests, we used an inplace actuating rod with approximately $25-\mathrm{mm}$ axial travel that allowed the pins to remain retracted during emplacement and to be driven into contact with the surrounding rock when they $r$ ached total depth. The entire assembly was suspended below an inflatable packer (see Fig. 6).

$A$ three-wire, 60-channel ambient reference junction block located in the alcove was used to terminate the th.rmocnuples and to connect them to the shielded copper pairs leading to the surface data-acquisition system. When surrounded with plastic foam insul ation, this large metal block with insulated connecting terminals imbedded in it provided a uniform (albeit varying with ambient temperature) "cold" junction.
The hlock temperature was monitored ini. rially by an attached thermocouple. The output of this thermocouple was processed by : "thermocouple transmitter unit" mounted next to the ref. erence block. This unit purportedly contained an equivalent ice-point reference and cirruitry to provide an output suitable to reference all the thermocouples to $0^{\circ} \mathrm{C}$. Jecause the unit proved to be noisy and temperature-sensitive. we used the lower thermocouple in the hole farthest from the heaters as a reference point during the first part of the experiment. iater, we drilled a long $(-15-\mathrm{m})$ hole into the wall of the drift across from the alcove and placed two spare thermocouples in it to provide a constant relerence temperature. Two more thermocouples in the experimental area were occasionally placed in an ice bath to provide a reference calibration. E: entually, we replaced the "transmitter unit" with a unit that proved to be at least 10 times as stable, although the earth itself was more stable. 


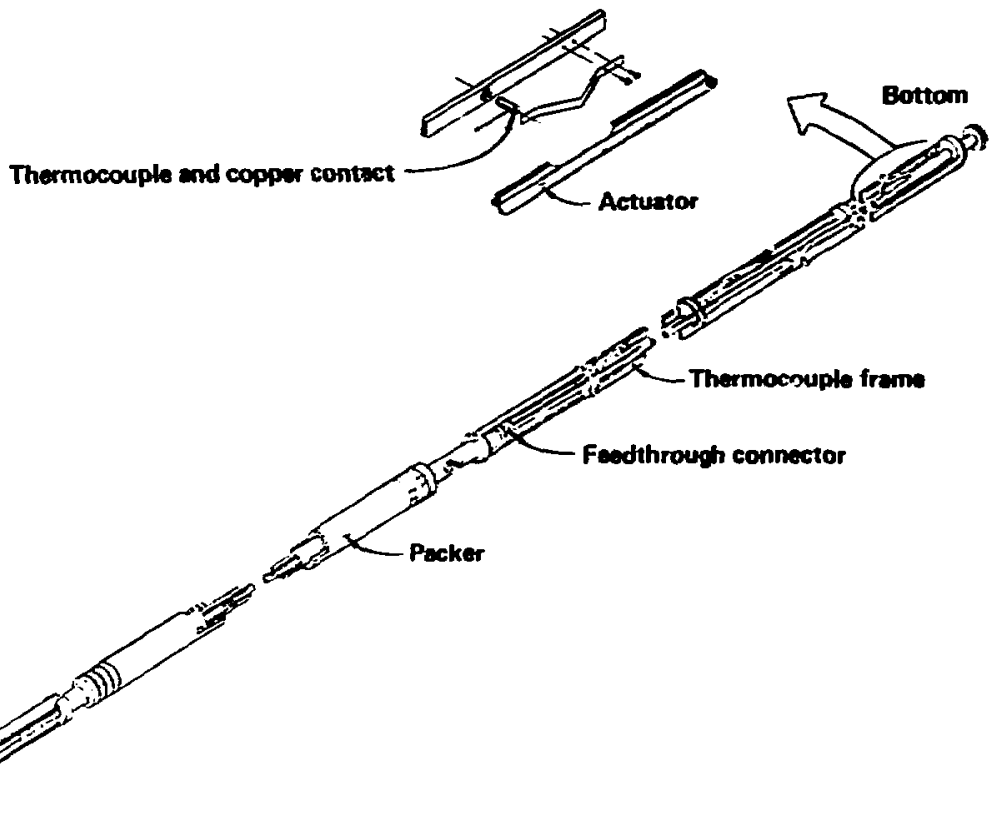

Figure 6. Thermocouple packer assembly.

\section{Packers}

Packers were fabricated using rubber sleeves banded to stainless steel pipe mandrels. Stainless steel tubes were welded through drilled holes in the pipe wall to inflate ihe packer and to cinntrol the pressure in the sealed portion of the role. Thermocouples were also emplaced within the pressurized region of the packed-off holes.

\section{Pneumatic Control Systen}

Air control and monitoring equipment was mounteci on a panel in the tunnel. Each of the five hoies instrumented for permeability testing was provided with two flexible nytun tubing strings. me for packer inflation and one to control hole pressure. Air was supplied frum a rack of compressed air bottles, packers were inflated with manual valves and dial gauges, and hole pressure was controlled by remotely controlled solenoids and pressure transducers. In this way, once the packers were set, experiments could be conducted entirely from the surtace, with no need tor tunnel arcess (Fig. 7 ).

\section{Pressure Transducers}

The Teledyne Taber Serie's 185 and Series 206 transducer units used for the permedbility experiment had an operating range of 0 to 300 psia. Each was calibrated at the LLNL standards laboratory and had an output linear to within $0.25 \%$ of fullscale. Repeatability was within $7,1 \%$ of the tultscale output. Within a compensated temperature range of -30 to $+170^{\circ} \mathrm{F}$, the thermal zero shift was less than $0.01 \%$ and the thermal sensitivity was within $0.005 \%$ of full-scale output per degree Fahrenheit.

\section{Data-Acquisition System}

Th.* Lat_-acquisition system was basically two 60-channel data logger units located on the surface in an air corditioned trailer near the shaft. Figure 8 is a schematic of the data and control system. A Flike Modei 220A was the primary 


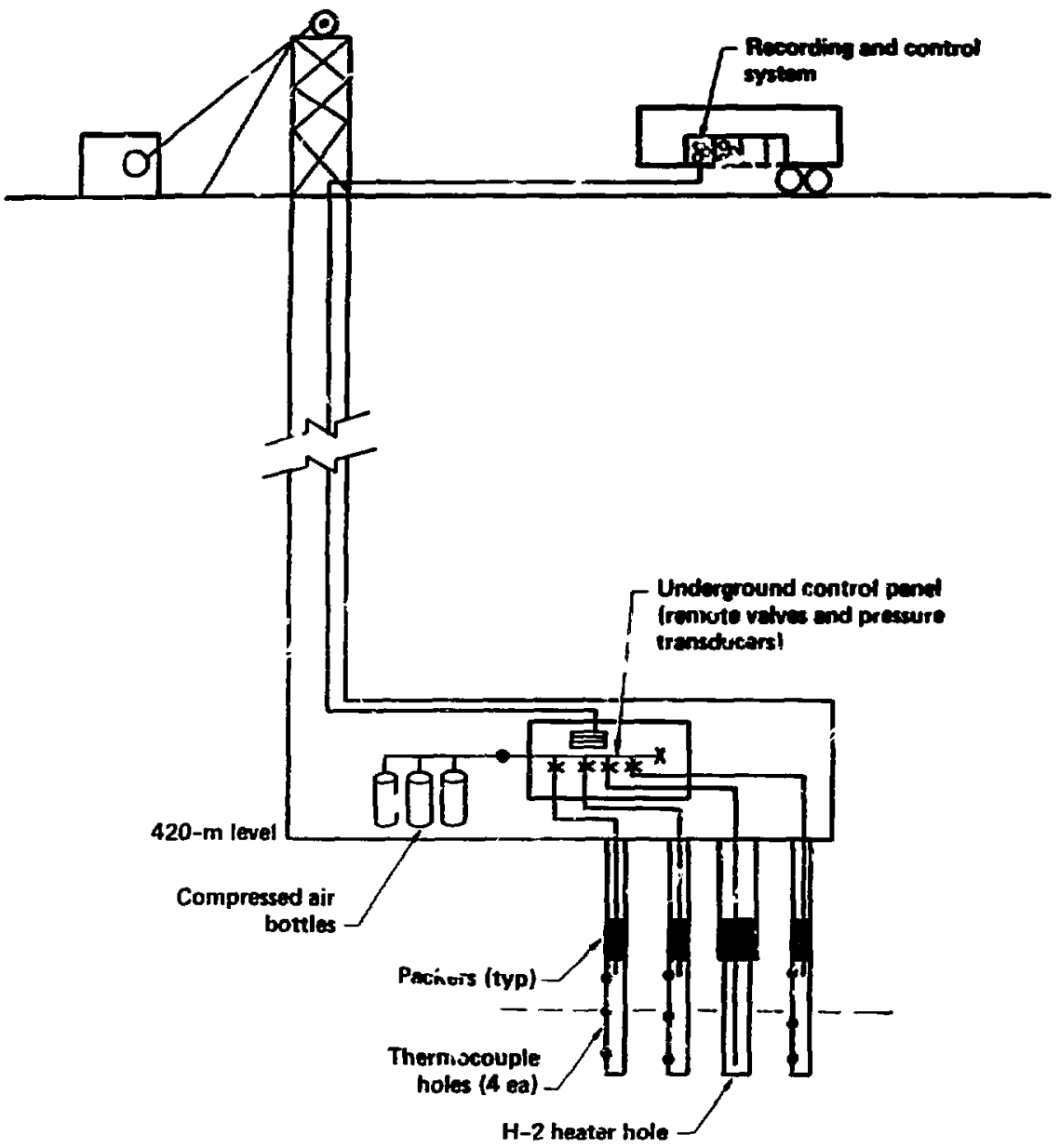

Figure 7. Pneumatic conl. ' system.

unit: a Vidar Model 5:03D was available as a backup. Although both units provided a hardcopy pintout of monitored voltazes and a magnetic tape recoiding of the same data, only one unit at a time could be used to record the data.

The system normally operated unattended. recording data at set in.ervals (usually one-half or one hour). Every workday, a terhnician che k.ed the system and called Live; more to report the latest data channel readings of interest. Each week (approximarely), the pnitout and magnetic tape were sent to Livermore for data reduction. 


\section{Data Reduction}

All data reduction was done at LLNL. No at'empt was made to combine signals such as reference voltages at the data-acqu' sition system or in the experimental area. This decision proved to be wise because it allowed us to choose, post facto, the best temparature reference(s) to use.

Data reluction was basically a three-step process:

1. The tape I $\mathrm{um}$ the field was copied to a disk file on one of the large computers at LLNL.

2. Errors were corrected where possible, and bad records were removed individually with an interactive text-editing routine.

3. The "cleaned-up" file was read and processed by a computer program written specifically for the experiment. Output consisted of hardicopy listings of raw and converted data and of files that cuuld be merged with previous output to produce ime-history data plots.

\section{Test Sequences}

The test sequences were not planned in great detail. The basic plan was to operate the first heater at somewhat less than maxisium power for a period of two to three weeks and then, depending on the behavior of the system, to change the power level periodically to obtain temperature histories from which both conductivity and diffusivity could be inferred.

The first heater test (H-1) usad the heater in the alcove and was ope ated for a tonal of 68 days from 14 October to 21 December 1977: its power history is shown in Fig. 9. To ensure that we did not overheat the heater, we br ught the povier up stepwise during the first few hours. After about nine days, the test begar. 10 conirol the sequence.

A small amount of water, probably tirculat. ing fluid lost to the facture syslem during drilling. entered the heater hole as vapor and began refluxing in a region near the top of the heater. This

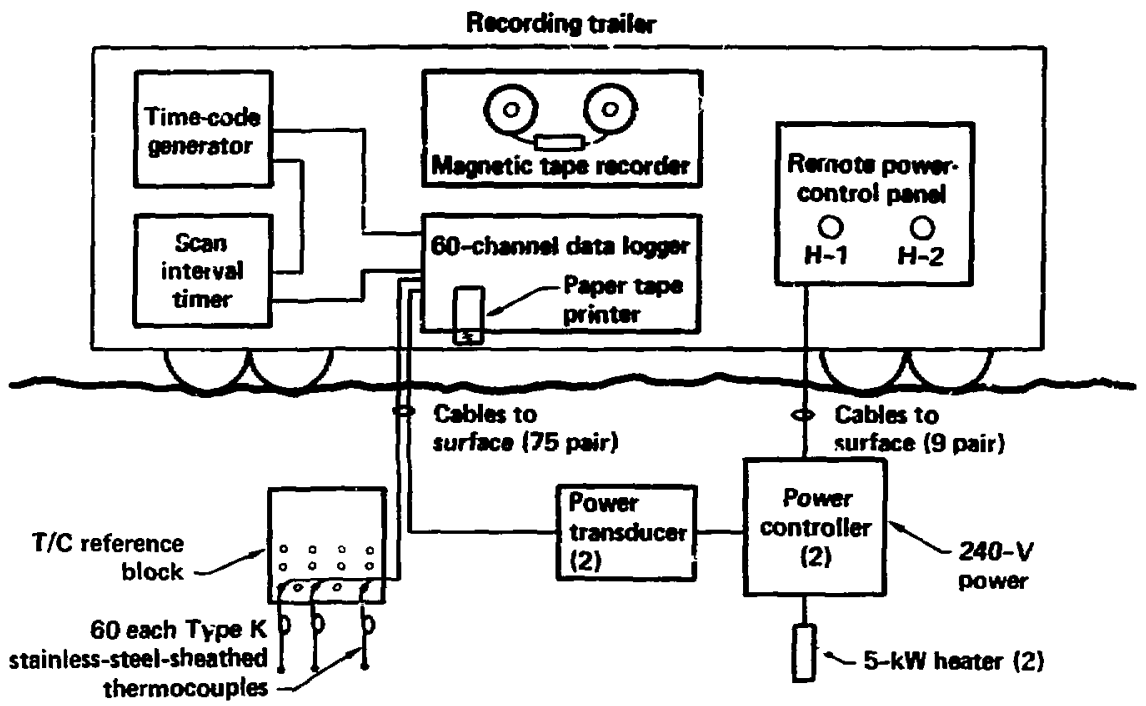

Figure 8. Data and control system for heater test. 
refluxing eventually caused a short circuit in the power leads, which, in turn, caused the SCR in the controller to fail open. After repairs were made, the system operated at the set power level for about a week until the controller failed full on and the power level rose to $4.8 \mathrm{~kW}$. This failure was apparently caused by a transient short circuit in a heater lead. Because the heater temperature at $\mathbf{4 . 8}$ $\mathrm{kW}$ was no: excessive and everything else was working well, we let the system nin this way for about one month. Then, we turnet the heater off for five days to make repairs. When the repairs were completed, we turned the heater back on at the original $3.7-\mathrm{kW}$ level and operated it for another three weeks.

The second heater test $(\mathrm{H}+2)$ used the heater in the drift and operated for 62 days from 21 December 1977 to 21 February 1978; its power his. tory is shown in Fig. 10. This test was intended to be similar (but not in detail) to $\mathrm{H}-1$. The only unanticipated power change was termination of the high-power $(4.8-\mathrm{kW})$ phase, when the temperature at the bottom of the heater began to rise. This excursion was subsequently associated with the accumulation of fine granite dust (probably drill cuttings) at the buttom of the heater. Water refluxing above the heater was also indicated; however, it caused no problem beciase of the improved configuration.

The permeability test ran for 83 days from 13 April to 7 July 1978. It included a total of seven pressurization test cycles, six of which yielded interpretable results. During calibration and checkout, we established, within the resolution of the instriment, that there was no pressurized air commiunication between any of the holes in the in- strument array. Permeability was obtained by airpressurizing each ho'e quasi-inslantaneously and observing the pressuse decay with time. Typically. during a 100-h period, the pressure would decline from $750 \mathrm{kl}^{*}$, to betiveen 700 and $730 \mathrm{k}$ ?a. The risuiution of the pressure-transducer recording was $0.05 \mathrm{kPa}$.

Ideally, no temperature change would occur during a permeability test: thus. all changes in pressure would be caused by fluid flow away from the drill hole. Because it would have taken months at each power level to attain a constant sock temperature at the range of the test holes, we reduced the power level before each pressurization test. which produced a nearly constant temperature during the first few days of testing (lig. 11). With thiv :exhnique. we were able to control test-hole temperatures to $\pm 1^{\circ} \mathrm{C}$ during the first two tests al elevated temperature.

Before energizing the heater, we ran an initial test and then conducted two additional texts at elevated temperature. To establish a maximum temperatire plateau. we then turned up the heater to full power. After $200 \mathrm{~h}$ at full power the he.iter failed internally; and we had to modify the test suquence to evaluate permeability durring the cool-down cycle. During this rycle, two valid tests were conducted.

These initial tests were cenducted in rosh that had been thermally cycled during the previous tests As a final check on in-situ permeabilities, we moved two of the test assemblies to holes near the intersection of the onthogonal array (I-06 and P. 01) so that we might evaluate the permeability of the rock mass in an area where no significant heating nad occurted.

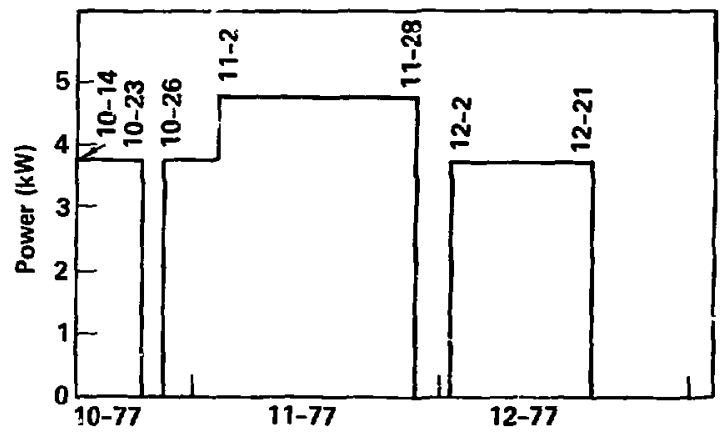

Figure 9. Pawer history of 11-1. 


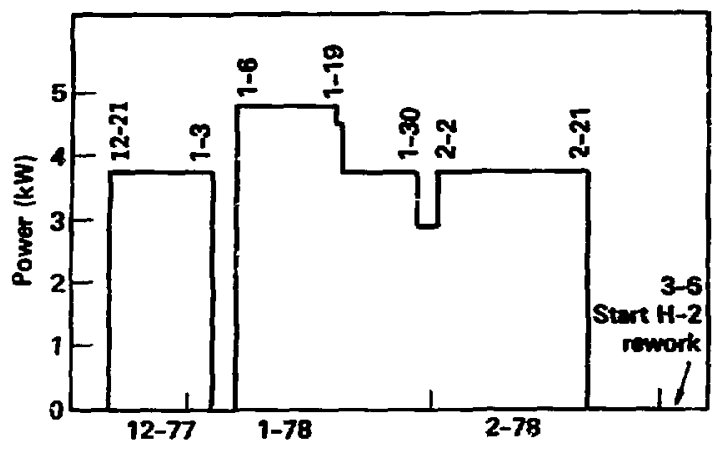

Figure 10. Power history of H-2

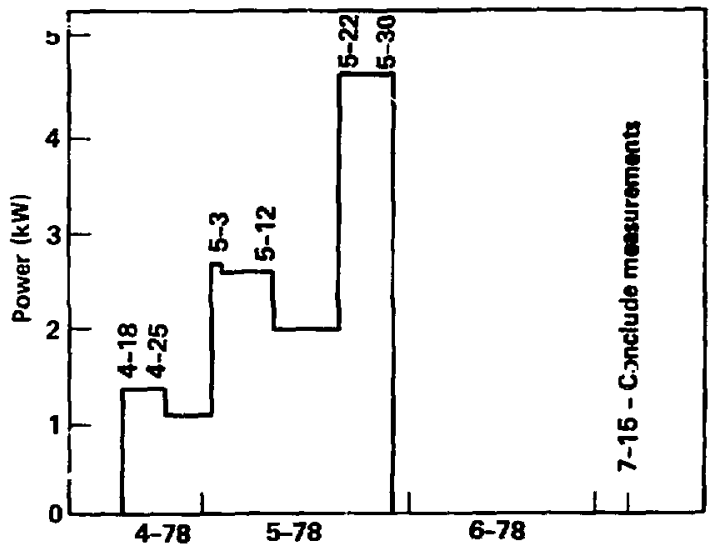

Figure 11. Power history for permeability test.

\section{Data Analysis}

\section{Heater Tests}

Our data analysis for the heater tests consisted primarily of comparing the measured and calculated temperature histories of selected thermocouples. To make the comparison, we varied the conductivity and diffusivity in the calculations until reasonable agreement between the measured and calculated temperatures was attained.

The calculational technique used was basically simple, namely the superposition in space and time of the continuous point-source solution of the diffusion equition

$$
\Delta T=\frac{Q}{4 \pi k d} e_{i t c} \frac{d^{2}}{4 \Delta t} .
$$

where

$\Delta T=$ temperature rise $(\mathrm{K})$

$Q=$ source strength (W)

$d=$ distance from point source $(m)$

$k=$ thermal conductivity $(W / m \cdot K)$

$\kappa=$ thermal diffusivity $\left(\mathrm{m}^{2} / \mathrm{s}\right)$

1 = time (s)

erfc $=$ complementary error function

We used a sufficiently large number of point sources to represent each finite-length heater so, 
at a distance corresponding to the nearest instrument holes, the combined solutions were essentially identical with that of a line-segment source. The material surrounding the heater was assumed to be isotropic, with constant thermal cond'ctivity and thermal diffusivity independent of temperature. For each heater test, we used the power history (i.e., Fig. 9 or 10) to determine appropriate values of $Q$ for the duration of each heating segment. Then we performed one calculation for each trial set of $k$ and $\kappa$ values. That is, the above formula has a fixed value of $\psi$ for each time period of fixed heater power; thus, temperature histories can be evaluated at any desired set of distances (d) from the source by summing the contributions of all poin. sources used to simulate the heater. Using super rosition in time, we combined the solution for each constant-power heating segment with the other constant $Q$ solutions to complete one full calculation for each trial set of $k$ and $\kappa$. Such calculations were used to produce temperature histories at distances corresponding to each thermocouple location.

\section{Heater Test Results}

The unplanned power loss during the $\mathrm{H}-\mathrm{I}$ test was most ureful for data ana!ysis. The temperature minimum at about $295 \mathrm{~h}$ proved to be the most sensitive region for purposes of comparison. especially for diffusivity. Figures 12 to 14 show a comparison of data and calculations for a $20-\mathrm{h}$ time span centered about the minimum. Tt. vata shown in these figures are from the two midplane thermocouples in hole $1-02(\sim 0.5 \mathrm{~m}$ from the heater). These measurements were made in a plane parallel to the principal fracture orientation (Fig. 2).The calculations show the sensitivity of the temperature of the medium to variations in conductivity, diffusivity, and location (any uncertainty in heate. power would affect the results inversely as a variation in conductivity). As expected, small changes in conductivity show a linear shift in temperature, while variations in diffusivity (which affects the time constant) show a shift in minimum temperature time and a crossover in calculaced temperature following the minimum. While a change in position shows a shift in temperature, the shift tends to be stronger during the heating phase than during cooling. Because the data show the same tendency, we suspect that the two thermocouples were not at the same radial position from the heater, but differed by a few millimeters because of rotation of the assembly during installation.

On the basis of the results of the sensitivity study described above, we used the values $k=$ $3.08 \mathrm{~W} / \mathrm{m} \cdot \mathrm{K}$ for thermal conduclivity and $\boldsymbol{x} \times$ $1.21 \mathrm{~mm}^{2} / \mathrm{s}$ for thermal diffusivity to calculate temperaute-rise-vs-time histories for each thermocoufle location. Plots of these calculations and the measured temperature rises are shown in Appendix $A$. The letter designations indicate loca. tions below the heater midplane $(A)$, at the midplane ( $B$ and $C$ ), and above the midplane ( $D$ ).

Agreement between the salculations and measurements varies. The worst cases are those in which the calculated temperature goes above the boiling point of water fa temperature rise of $\sim 73^{\circ} \mathrm{C}$ over the ambient temperature of $\sim 23^{\circ} \mathrm{C}$ ). In these cases, water-probubly from residual drilling fluid-boils and the resulting steam rises. condenses to liquid water in a cooler region, and runs back to be broiled again. The result is a reflux zone clamped at the boiling point, or a heat pipe transfierring hral from the bottom of the zone to the top.

When and where boiling water effects were not important, the heater lest data appear to fit with values near $k=3.1 \mathrm{~W} / \mathrm{m} \cdot K$ for thermal conductivity and $\alpha=1.2 \mathrm{~mm}^{2} / \mathrm{s}$ for thermal diffusiv. ity. As noted above, these values were obtained from measurements in the plane parallel to the principal fracture direction. Wic observed that the level of agreement between measured and calculated temperature histories is nearly as good in the orthogonal tirection. For example, compare 1-01 (p. A-3) witt. 1-11 (p. A-9) and I-03 (p. A-6) with I09 (p. A-12). Since errors in temperature rise are inversely proportional to errors in conductivity, we conclude that the anistropy in the thermal properties of the rock is on the order of a lew percent. These results are consistent with other measurements for granitic rock at the Nevada Test Site. In 1960 the U.S. Geological Survey reported on the thermal conductivities of 14 core sample; from the U15a No. 31 exploration hole.' These samples, taken from a depth of 19 to $366 \mathrm{~m}$, had an average value of $2.62 \mathrm{~W} / \mathrm{m} \cdot \mathrm{K}$, with a standard deviation of 0.31 . In 1982 Durham ${ }^{*}$ reported on the measurements of three samples, one from the $\mathrm{H}-2$ hole and two from a hole $-75 \mathrm{~m}$ to the southwest. He gives thermal conductivity and diffusivity values as $k=2.75 \pm 0.25 \mathrm{~W} / \mathrm{m} \cdot \mathrm{K}$ and $\kappa$ $=1.25 \pm 0.4 \mathrm{~mm}^{2} / \mathrm{s}$, respectively. While the mean ccnductivity may apprear to be significantly different than the value we determined here $(3.08$ 

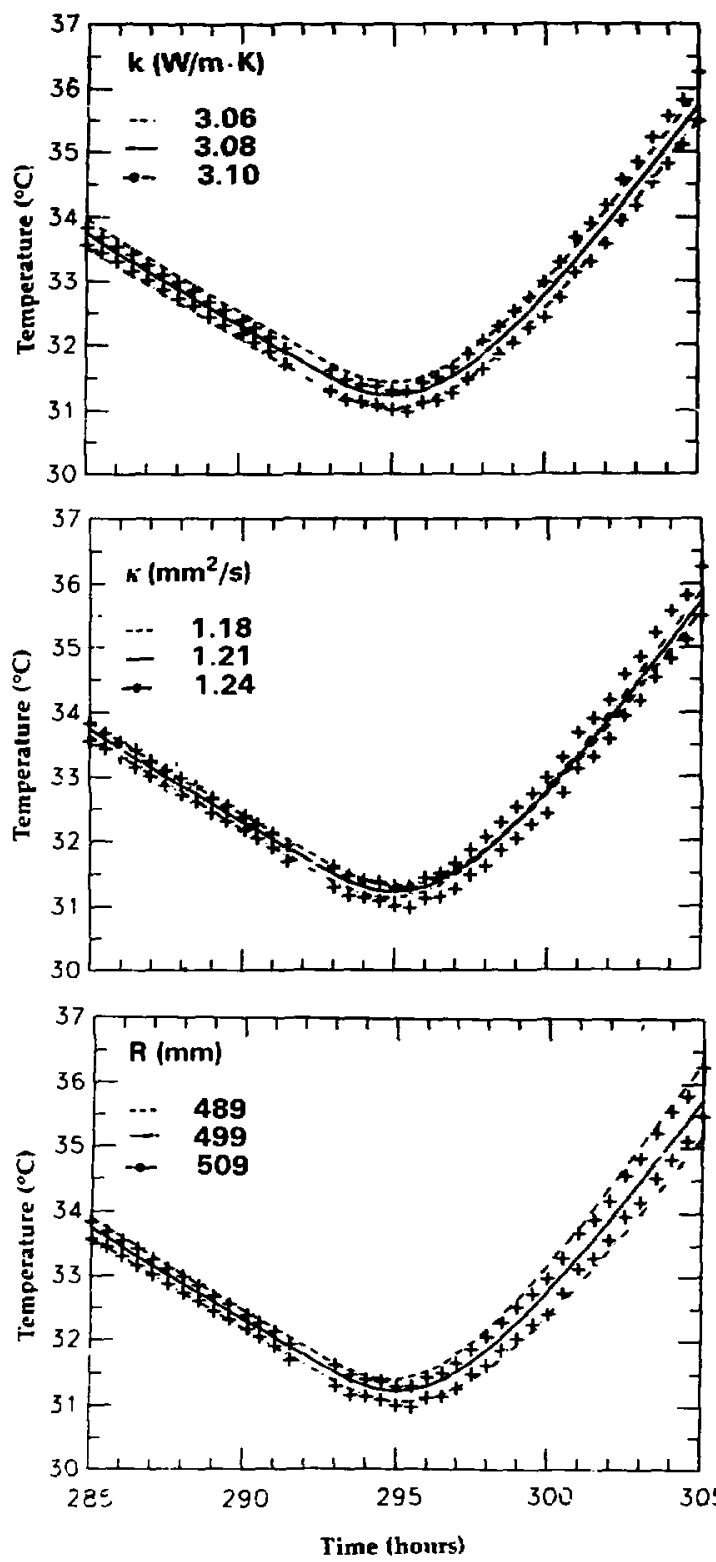

Figure 12. Measured and calculated data for 20-h time span from two midplane thermocouples in hole 1-02, shawins sensitivity with respect to conductivily. Here $\mathrm{N}=121 \mathrm{~mm}^{2} / \mathrm{s}$ and $R=499 \mathrm{~mm}$.

Figure 13. Measured and calculated dala for 20-h time span from two midplane thermocouples in hole 1-02, showing sensitivity with respect to diffusivily. Here $k=3.08 \mathrm{~W} / \mathrm{m} \cdot \mathrm{K}$ and $R=\$ 99 \mathrm{~mm}$.

Figure 14. Measured and calculated dala for 20-h time span from two micingane thermoccuples in hole $\mathrm{I}-02$ shot ing sensitivity with respect to distance. Here $k=3.08 \mathrm{~W} / \mathrm{m} \cdot \mathrm{K}$ and $\kappa$ $=1.21 \mathrm{~mm}^{2} / \mathrm{s}$. 
$\mathbf{W} \mathbf{m} \cdot \mathrm{K}$ ), examination of Durham's (Durham 1982) data shows that this is not the case. Conductivities cluster near $2.6 \mathrm{~W} / \mathrm{m} \cdot \mathrm{K}$ for one sample and near $3.0 \mathrm{~W} / \mathrm{m} \cdot \mathrm{K}$ for the other. Given the small sample size and known heterogeneity of the granite, such variability is anticipated. The in-situ measurements are a more accurate reflection of the average over a large volume.

\section{Permeability Data Analysis}

The data analysis for the permeability test was based on Jaeger's (1956) solution for the coolIng of a heated infinite cylinder. His power series expansion," when written in terms of fluid flow in a porous medium for the pressure decay in an infinite cylindrical hole with an initial pressure $P_{11}$ in a homogeneous isotrupic medium. is

$$
\begin{aligned}
\frac{P}{P_{11}}=1 & -\frac{4}{\sqrt{3}} \phi \tau^{1}=+\phi(4 \phi-1) \tau \\
& + \text { terms } 0 \tau^{i}=\text { etc. }
\end{aligned}
$$

or

$\frac{P}{P_{\mathrm{l}}}=1-\frac{t}{\sqrt{3}} \phi \tau^{\mathrm{J}}=-\phi t$ for small $\phi$ and $t$.

where

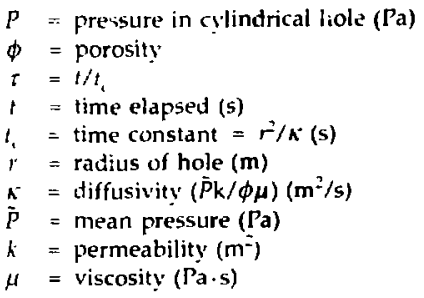

The use of a pure radial-flow solution (infinite cylinder) seems intuitively reasonable berause of the high length-to-diameter ratio $(\sim 60)$ of the packed-off section of the holes. The error introduced by the radial-flow assumption is of interest and has received considerable study in the analogous field of using probe methods to determine the thermal properties of materials in bulk. Following Blackwell (1953), ${ }^{10}$ we find the relative error in the calculated pressure is approximately erf $(\lambda / 2, \tau)$, where $\lambda$ is the length-to-diameter ratio. For most of our permeability measurements, the value of $\tau$ at the end of the measurement was in the range 1 to 10 , giving a negligible error. In only one case (P-01, nun S) was $r$ large $(-300)$. This indicates a relative error of only 0.015 .

Adapting the linear form of the diffusion equation (applicabln in heat flow) to the inhercatly nonlinear probiem of porous flow of a compressible gas requires some attention. A common way to "linearize" the gas-flow problem is to use $\tilde{p}=\left(P_{m s}+P_{m m n}\right) / 2$, particularly when the pressures are not too different. In our case. however. the pressure ratio $P_{1} / P_{\text {smtranm }}=N-10$, and further consideration seemed prudent.

To belter approximate $\bar{P}$, we considered a related problem of one-dimersional Cartesian now in a semi-infinite medium having a constant pressure boundary. This problem was first studied by Wagner (1950)" in terms of nonlinear chemical diffusion. His results are equivatent to the pres. sure ratio $N=x$. Morrison $(1972)^{1:}$ studied the same problem and extended the solutions to finite $N$. The problem can be solved numerically, using only two :ariables for a given N. by Boltzmann's similarity transformation. The results may be expressed as

$\Phi=f(\theta, N)$.

where $\Phi$ is a dimensionless pressure or concentration and the spact-time variable $\theta$ is given (using Morrison's (omulation) by

$$
\theta^{2}=\frac{X^{2} \phi \mu}{4 h t \Delta P}
$$

We can compare this solution to the linearized solution of the diffusion equation for the same geometry. If we use the linear form of the diffusion equation and replace $\Delta P$ with $\bar{P}$, the solution is

$$
\Phi_{11,}=\operatorname{erfc}\left(\theta_{1 m}\right)
$$

To obtain a usable approximation fror $\tilde{P}$, we match the linear and nonlinear solutions at the boundary $(\theta=0)$. Because the solutions are normalized to one at $\theta=0$, we have the first derivatives at our disposal. Thus, the linear and rionlinear solutions will agree in both value and flow rate at the surface if we set

$$
\frac{\left(\left.\frac{\mathrm{d} \Phi}{\mathrm{d} \theta}\right|_{\theta}\right)_{\ln }}{\theta_{\mathrm{in}}}=\frac{\left(\left.\frac{\mathrm{d} \Phi}{\mathrm{d} \theta}\right|_{\|}\right.}{\theta}=
$$

giving 
$\tilde{p}=\left.\Delta P \frac{\left(\frac{d \Phi}{d \theta}\right)^{2}}{\left(\frac{d \Phi}{d \theta}\right)^{2}}\right|_{\text {lin }}$

From the properties of the error function, we have

$\left(\frac{d \Phi}{d \theta}\right)_{\ln n}=-\frac{2}{\sqrt{\pi}}$

and from Morrison ${ }^{13}$

$\left(\frac{d \Phi}{d \theta}\right)_{,} \quad=-0.86985$.

both calculated at $\theta=0$. This adjusts our approximation for $\bar{p}$ to

$\tilde{P}=\frac{\Delta P}{1.68}$

instead of the $\tilde{P}=\mathcal{A} P_{\ldots}$ sometimes used for linearized problems. We then use this "adjusted" value of $\hat{P}$ in the linearized solution for the infinite cylinder. This allows us to include the effects of radial flow that were not included in the nonlir.ear solution for the planar problem.

In the above discussion of test sequences we mentioned that the ideal permeability test would be conducted at constani temperature so that pressure change in the hole would be due entirely to fluid flow into the drill-hole walls. By adjusting the power levels iust before each pressurization test, we obtained nearly constant temperatures when the heater was operational. Figure 15 shows a temperature curve for a pressurization test hole located $\mathbf{0 . 4} \mathrm{m}$ from the heat source. This curve is representative of the temperature histories in all of the pressurized holes. The seven pressurization tests are indicated in Fig. 15 by letter designations $M$ through $S$. The length of each pressurization cycle and the change in temperature that cccurred during each test can also be seen in Fig. 15. During tests $M, N$, and $O$, relatively constant temperatures were achieved, as planned. After the heater failed, $P$ experienced large changes in pressure and, thus, failed to yield usable data. Subsequent tests durine the cooling portion of the history (tests $Q, R$, and $S$ ) were close enough to constant temperature that temperature corrections to the hole pressure lead, by the above formula, to a usable interpretation of the pressure decay.

For each pressurization test, we took the pressure at any time in " $u$ :h hole and "corrected" it to

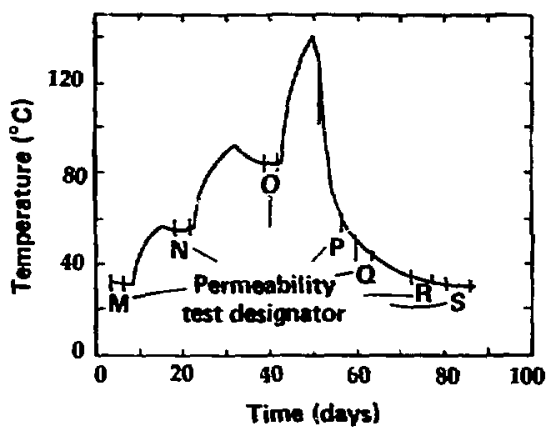

Figure 15. Temperature hislory of permeability test at $0.4 \mathrm{~m}$ from heater.

what it would have been at the starting temperature. We did this by multiplying the pressure by the ratio of the absolute temperature at a given time to the starting temperature in that hole. That is, we assumed an equation-of-state linear with absolvte temperature for the air pressiurizing the hole, such as the ideal gas equation $P=\| R T / V$. The temperatures for this correction were obtained by averaging the values for the four thermocouples in each pressurization test hole. The "corrected" pressures, $P$, were then plotted as $P$ vs it and fit, using standard least-squares techniques, ir a function of the form

$P=P_{n}+P_{1} t+P_{2}$,

giving as a parabola the $P$ vs 1 curve. The resulting parabolic curves, together with the actual data used to obtain the least-squares fit, are shown in the upper half of each figure in Appendix B. In each of the least-squares fits to the data, the first few pressure points obtained immediately after pressurization did not lie on the best-fit parabola for the remainder of the data. Yet, the remainder of the data was extremely close to a parabola. This effect of the first few points not lying on the bestfit parabola becomes clearer if we rearrange the above formula and plot the data in a form that should result in a straight line:

$$
\frac{1-\frac{P}{P_{11}}}{i t}=A+B, t \text {. }
$$


Then, if the data for each pressurization test are plotted as $\left(1-P / P_{n}\right) /, t$ vs, $t$ and the pressure decays according to the approximation used, the resulting curve should be a straight iine. The bottom figures in Appendix $\mathbf{B}$ show both the straightline fits to the data and the data used for each pressurization test in each hole. In these plots one can easily see that the early-time poinis (for about the first hour after pressurization) are usually badly scattered. After the first hour, however, the data are quite close to linear for most of the holes. We interpreted this nonlinear behavior during the first hour as the result of disturbances in both the temperature and stress state caused by the sudden injection of - 100-psi air at ambient temjerature. Thus, we usually avoided using these first few data points in the data fit for the best straight line through the pressure decay data.

Our data-reduction program allows the user to specify some number of points at the beginning and/or end of the data that are to be ignored in the curve fitting. It also allows the user to select a tolerance level, in standard deviation units, for the data points $+\checkmark$ be accepted. All data are shown in the plot as circles (to be ignored) and crosses (to be used). 1.1 the plots in Appendix $B$ the first 14 points anc' any point exceeding 2.5 sigma are ignored. Appendix B contains the data for and anal$y$ sis of all se $s$ that gave meaningful results. It also contains the data and analysis for test $\mathrm{O}$, hole J-02 (Fig. B-10), which shows a typical bad result. Here, the noise in the data (although small) is greater than the total pressure drop and leads to negative permeability and porosity. By contrast, test $\mathrm{O}$, hole $\mathrm{H}-2$ (Fig. B-9), the only heater hole data to show positive results, has more than five times as much scatter in the data (presumably the result of temperature fluctuations caused by fliccuations in line voltage), but a much greater pressure drop.

We calculated the permeability and porosity from the values obtained for $A$ and $B$ in the bestfit straight line: $k=\frac{\dot{r} \mu}{\tilde{P}} \mathrm{~B}$

and

$\phi=\frac{\pi \mathrm{A}^{2}}{16 B}$.

where $r=24 \mathrm{~mm}$ anit $\mu=1.75 \times 10^{\circ} \mathrm{Pa} \cdot \mathrm{s}$.

The constants $A$ and $B$ were calculated from the constanis $P_{12} P_{1}$, and $P_{2}$ of the quadratic leastsquares fit.

\section{Permeability Test Results}

Table 2 is a summary of the average permeabilities obtained in the various pressurization tests. Included are the average permeabilities, porosities, temperatures, and root-mean-square residuals resulting from the curve fitting. The residuals are generally well below the manufacturer's stated transducer repeatability o; $0.3 \mathrm{psi}$.

Note that the permcability value: are sub. stantially different from those reported previ ously. This is a result of the improved analysis method described above. The permeability obtained at ambient temperature was approximately $1 \mathrm{nD}$. At about $56^{\circ} \mathrm{C}$ above ambient (during heating), the permeability decreased to $02 \mathrm{nD}$; at higher temperatures, it became too small to measure $(<0.02 \mathrm{nD})$. Upon subsequent cooling, the permeability returned to approximately its preheat value of $1 \mathrm{nD}$. The ambient-temperatuse permeabilities of regions that had been thermally cycled to high temperatures before the pressurization tests (i.e., during the heater tests) were approximately the same as those in regions that had not undergone thermal cycling.

\section{Conclusions}

The in-situ conductivity value of $3.1 \mathrm{~W} / \mathrm{m} \cdot \mathrm{K}$ obtained from the heater tests is consistent with other measures in Climax Stock granite. The insitu diffusivity was approximately $1.2 \mathrm{~mm}^{2} / \mathrm{s}$. Anisotropic effects in the thermal field were less than $10 \%$. The good agreement between the calculated and experimental temperature histories for all thermocouple stations us!ng the above values for $k$ and $x$ gives credence to the results of analyses using similar values to predict the thermal fields resulting from emplaced nuclear waste and heaters at the Spent Fuel Test-Climax.'

Our heater tests provided valuable lessons on how to obtain good thermal data in situ. In par- 
Table 2. Permeability test results (see Fig. 15 for test sequence designator).

\begin{tabular}{|c|c|c|c|c|c|c|c|c|c|c|c|c|c|c|c|c|c|}
\hline $\begin{array}{l}\text { Borehole' } \\
\text { domignator }\end{array}$ & $\begin{array}{c}\text { Distance } \\
(\mathrm{m})^{4}\end{array}$ & & 1 & 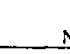 & & $c$ & & & & 0 & & I & 2 & & $\underline{s}$ & & \\
\hline $\mathrm{H}_{2}$ & 0.0 & $\begin{array}{c}b \\
32.4\end{array}$ & $\begin{array}{c}p \\
0.016\end{array}$ & $\frac{b}{290.9}$ & $\begin{array}{c}b \\
0.049\end{array}$ & $\begin{array}{r}1.09 \\
+19.3\end{array}$ & $\begin{array}{l}0.0071 \\
0.082\end{array}$ & $\begin{array}{r}b \\
85.0\end{array}$ & $\begin{array}{c}b \\
0.2 h l\end{array}$ & זין & & $\mathrm{PF}$ & & $\mathrm{PF}$ & & $\begin{array}{l}\text { lesm., } \\
\text { A, nD }\end{array}$ & $\begin{array}{c}\text { Purosity. } \\
\phi\end{array}$ \\
\hline$|\cdot 12|$ & 0.4 & $\begin{array}{l}0.401 \\
32.3\end{array}$ & $\begin{array}{l}0.0028 \\
0.007\end{array}$ & $\begin{array}{l}0.15 \\
51.2\end{array}$ & $\begin{array}{l}0.0010 \\
0.009\end{array}$ & $\begin{array}{c}b \\
74.3\end{array}$ & $\frac{b}{0.015}$ & $\mathrm{PF}$ & & $\mathbf{F F}$ & & $\Gamma F$ & & $\mid \mathbf{l}$ & & $\begin{array}{l}\text { Temp., } \\
\text { t, }{ }^{\circ} \mathrm{C}\end{array}$ & $\begin{array}{l}\text { Residual } \\
\text { error, psi }\end{array}$ \\
\hline 1.019 & $0,7,3$ & $\begin{array}{l}11.62 \\
32.4\end{array}$ & $\begin{array}{l}0.001+7 \\
0.0107\end{array}$ & $\begin{array}{l}0.13 \\
+3.6\end{array}$ & $\begin{array}{l}0.0103 \\
0.007\end{array}$ & 59.4 & $\frac{b}{0.014}$ & $\begin{array}{l}0.070 \\
70.9\end{array}$ & $\begin{array}{l}0.002^{9} \\
0.1600\end{array}$ & $\begin{array}{c}0.93 \\
46.8\end{array}$ & $\begin{array}{l}0.00: 1 \\
0.009\end{array}$ & $\begin{array}{l}1.08 \\
36 .+\end{array}$ & $\begin{array}{l}(0.018 \\
0.10) 6\end{array}$ & NI & & & \\
\hline 1111 & 19.37 & $\begin{array}{l}1111 \\
32+\end{array}$ & $\begin{array}{l}0.00,31 \\
0.007\end{array}$ & $\begin{array}{l}0.24 \\
5.34\end{array}$ & $\begin{array}{l}0.0 H^{15} 3 \\
0.017\end{array}$ & $\begin{array}{c}b \\
7 \times-4\end{array}$ & $\begin{array}{c}b \\
n 062\end{array}$ & $\begin{array}{c}b \\
\text { sil }\end{array}$ & $\begin{array}{c}b \\
00+3\end{array}$ & $\begin{array}{l}078 \\
+7=\end{array}$ & $\begin{array}{l}0.0013 \\
11.00 \mathrm{H}\end{array}$ & $\begin{array}{l}116 \\
36,6\end{array}$ & $\begin{array}{l}0.0(x) \cdot 4 \\
\text { ll. (x) }\end{array}$ & NI & & & \\
\hline 111 & 10.4 & $\begin{array}{l}11.64 \\
32.3\end{array}$ & $\begin{array}{l}0.010101 \\
13.0(10)\end{array}$ & $\begin{array}{l}0.13 \\
51 ?\end{array}$ & $\begin{array}{l}001012 \\
0018\end{array}$ & $\begin{array}{c}6 \\
74.1\end{array}$ & 0.067 & $\underset{P H}{b}$ & $\frac{b}{0.177}$ & $\begin{array}{l}1.03 \\
+75\end{array}$ & $\begin{array}{l}0.00125 \\
1006\end{array}$ & $\underset{16.5}{1.27}$ & $\begin{array}{l}0 .(0) 1.3 \\
0.007\end{array}$ & $\begin{array}{c}131 \\
33.7\end{array}$ & $\begin{array}{l}0.0010 \\
0.0199\end{array}$ & & \\
\hline $1.0 \mathrm{k}$ & +47 & $\mathrm{NI}$ & & Nl & & NI & & NI & & ו & & וא & & $\begin{array}{l}0 k B \\
26 \%\end{array}$ & $\begin{array}{l}0.0013 \\
0.0^{\prime} 0\end{array}$ & & \\
\hline ru & 923 & $\mathrm{Ni}$ & & NI & & VI & & NI & & NI & & NI & & $\begin{array}{l}1.67 \\
2 B 2\end{array}$ & $\begin{array}{l}0.301 \\
0015\end{array}$ & & \\
\hline
\end{tabular}

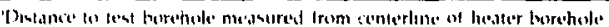

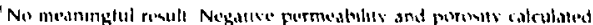

Ni met matrumented

i) Mather lallure 
ticular, they reinforced our intuition that the earth itself provides a more stable temperature reference than expensive commercial gadgets. In general, we found that the thermocouples and pressure gauges were more accurate than the manufacturer's conservative specifications, which are based on interchangeability requirements. For example, the specifications referred to absolute temperature values that were only accurate to $\pm 2^{\circ} \mathrm{C}$, bui we found that temperature changes of a few hundredths of a degree were consistently detected and reproduced in our analysis of the temperature histories. We also learned that datareduction programs should be operational before in-situ measurements are taken so that a feedivack of results is immediatcly available. The kind of data analysis used in these tests can tolerate nat $u^{-}$ ral self-cycies (such as heater failure) while providing data that are just as useful and valid as those obtained from planned ideal test sequences.
The permeability or the granite was low at ambient temperature $(\sim 1 \mathrm{nD})$, and thermal $\mathrm{cy}$ cling did not cause significant changes in its permeability. After high-temperature $\left(\sim 150^{\circ} \mathrm{C}\right)$ excursions, the permeability was approximately the same as that measured in rock that had never been heated. Wo could interpret the significant decrease in this already low apparent permeability with increasing temperature as implying that the permeability of the inlact rock was essentially zero, with the actual pressure decay in the tests being due primarily to the fracture for microfracture) flow of the gas. However. we know that the increasing temperature carses increasing compressive stresses in the surrounding rock. closing the available fractures and. thus, causing the apparent permeability to decrease significantly as the fractures close

\section{Acknowledgments}

This project was sponsored initially by the Energy Research and Development Agers! ..d then by the Department of Energy, Office of Nuclear Waste Isolation, through the Nevada Operations Office. We wish to thark these sponsoring agencies for their continuous support of the project.

Our thanks also go to the many individuals who worked on or contributed to the project. Special acknowledgments go to L. D. Ramspett, Waste Isolation Projects Manager at LLNL, to I.. B. Ballou, who provided overall technical leadershif and assisted with the data reduction and analysis, to $W$. $C$. Brough for the design, fielding, and survival of the data-acquisition system, to $O$. $R$. Walton for reviewing and assisting with the editing of parts of this report, and to the late F. A. Morrison, Ir., for helpful discussions relating to the permeability data analysis.

\section{References}

1. D.N. Montan and W. Patrick, Thermal Calculations for the Design, Construction, Operation, and Eraluation of the Spent Fuel Test-Climax. Nevada Test Site, Lawrence Livermore National Laboratorv. 1.ivermore, CA, UCRL-53238 (1981).

2. L. D. Ramspott, Ed., Waste Isolation Projects-FY1977, Lawrence Livermore National Laboratory, Livermore, CA, UCRL-50050-77 (1978).

3. L. D. Ramspott, Ed., Waste Isolation Projects-FY1978, Lawrence Livermore National Laboratory, Livermore, CA, UCRL-50050-78 (1979).

4. L. D. Ramspott, Climax Granite Test Results, Lawrence Livermore National Laboratory, Livermore, CA, UCID-18502 (1980).

5. L. B. Ballou, Geological Disposal Investigations in Granite at the Nevada Test Site, Lawrence Livermore National Laboratory, Livermore, CA, prepririt UCRL-82284 (1979).

6. W.L. Ellis and J.E. Magner, Determination of the In Situ State of Stress at the Spent Furl Test Climax Site, Climax Stock, Nevada Test Site, U.S. Geological Survey, Open File Report 82-458 (1982).

7. G. A. Jzet, Granitc Exploration Hole, Area 15, Nezada Test Site, Nye County, Nevada-Interim Report, Part C. Physical Properties, U. S. Ceological Survey, TFM-836-C (1960). 
B. W. B. Durham, Thermal Properties of Climax Stock Quartz Monzonite to $523 \mathrm{~K}$ and $50-M P a$ Confining Pressure, Lawrence Livermore National Laboratory, Livermore, CA, UCRL-53349 (1982).

9. J. C. Jaeger, "Conduction of Heat in an Infinite Region Bounded Intermally by a Circular Cylinder of a Perfect Conductor," Awst. J. Phys. 9, 167-179 (1956).

10. J. H. Blackwell, "Radial-Axial Heat Flow in Regions Bounded Internally by Circular Cylinders," Can. J. Phys. 31, 472 (1953).

11. C. Wagnet, "Diffusion of Lead Chloride Dissolved in Solid Silver Chloride," I. Chem. Phys. 18, 1227 (1950).

12. F. A. Morrison, Jr., "Transient Gas Flow in a Porous Column," Ind. Eng. Chem. Fundam. 11, 191 (1972).

13. F. A. Morrison, Jr. Lawrence Livermore National Laboratory, Livermore, CA, private communication (1983). 
Appendix A

Heater Test Data and Calculations

A-1 - 2 

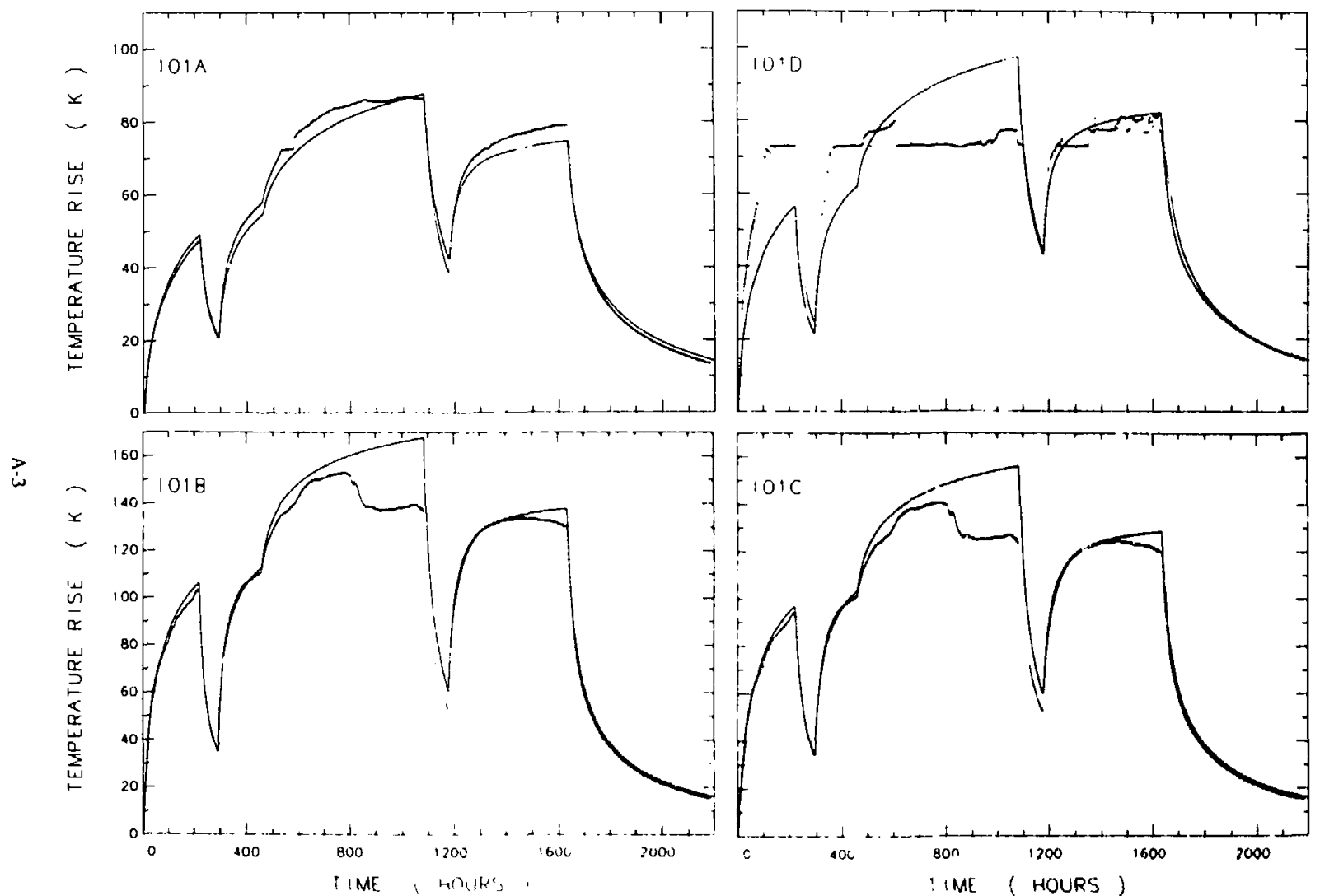

Figure A-1. Calculated and measured temperalure hintories for test using heater H-1, borehole l-01. Alphabetir cades are $A$ - below heater, $B$ and $C$. al heater midplane, and $D$ above heder midplane. 

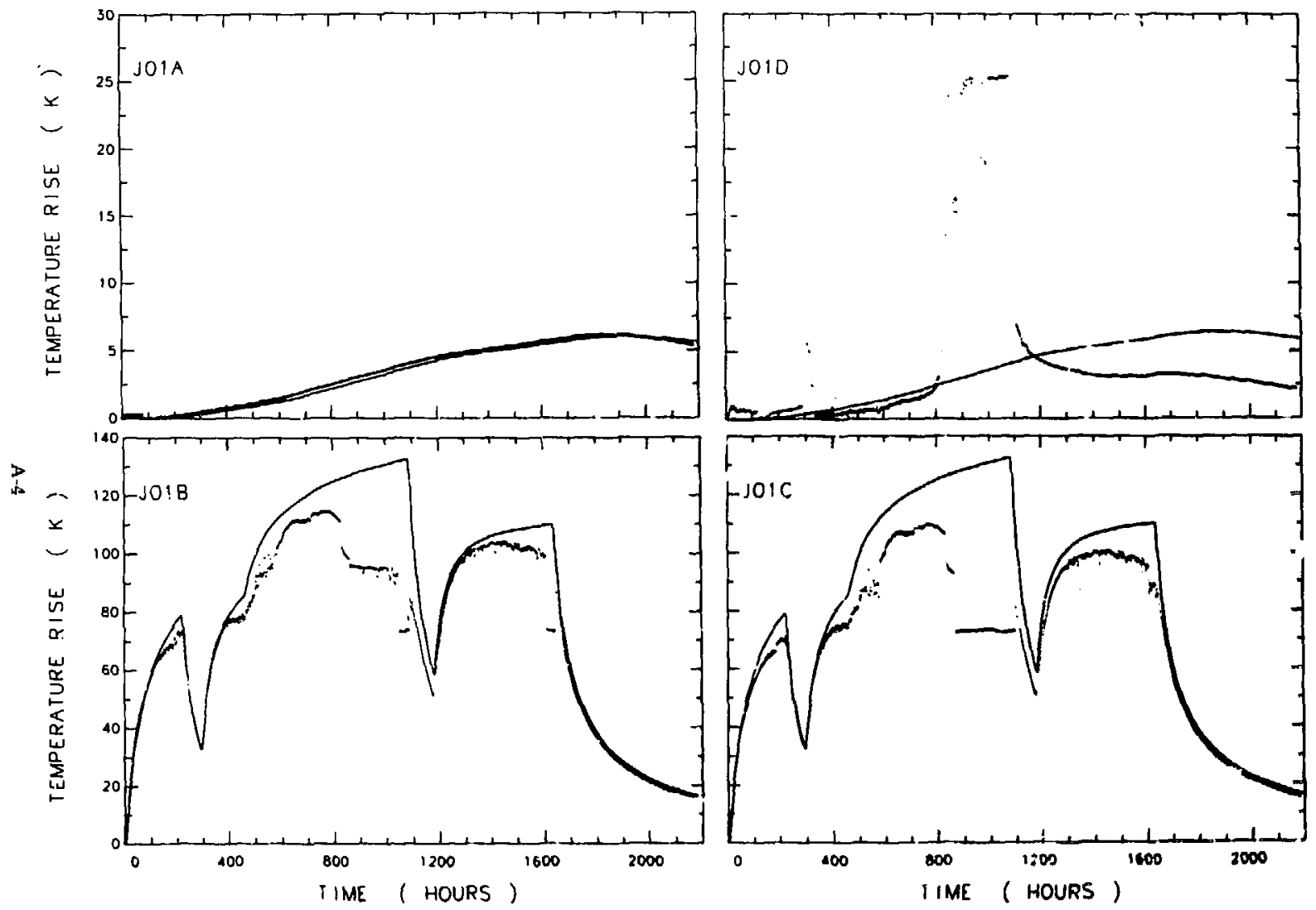

Figure A-2. Calculated and measured temperature histories for test uning heater H-1, borehole J-01. Alphabefic codes are A $=$ bulow heater, $B$ and $C=$ at heater midplane, and $D=$ above heater nidplane. 

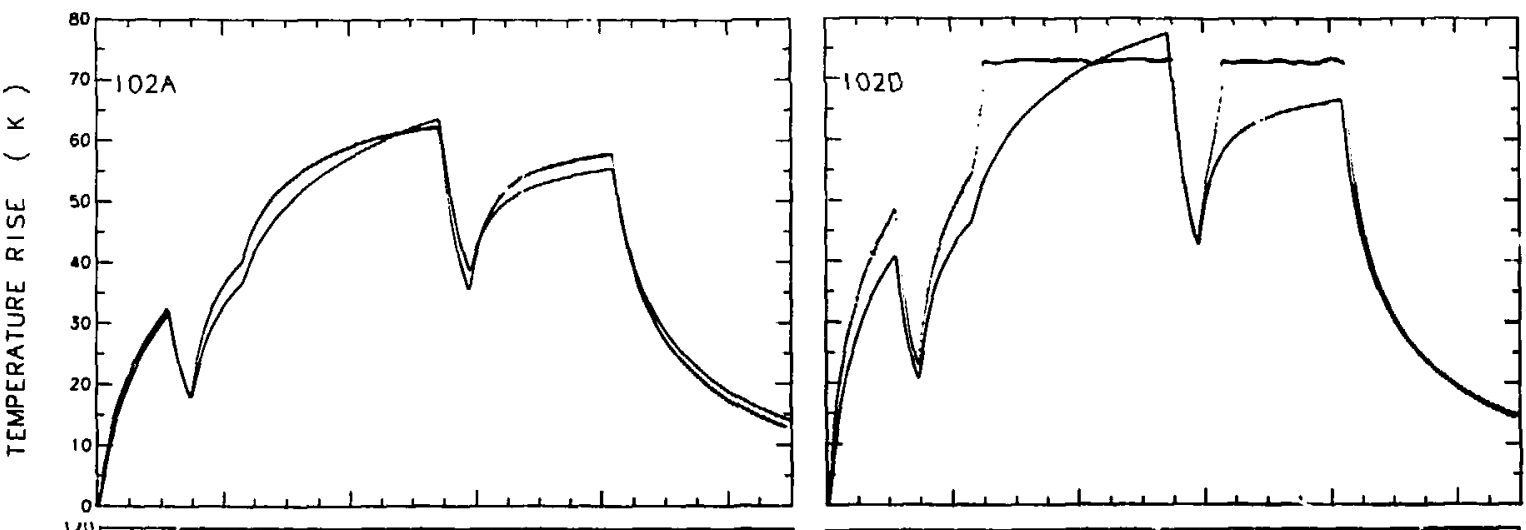

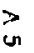
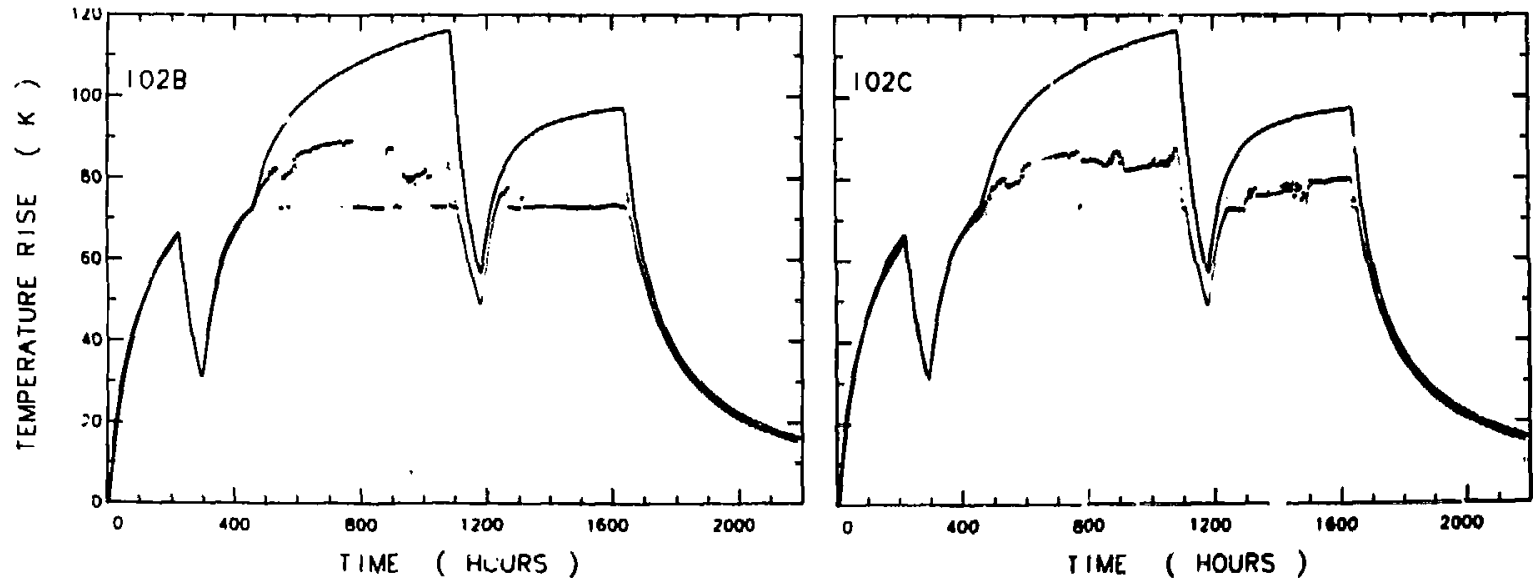

Figure A-3. Calculated and measured temperature histories for test using heater H-1, borehole I-02. Alphabetic codes are A $=$ below heater, $B$ and $C=$ at heater midplane, and $D$ is above heater midplare. 

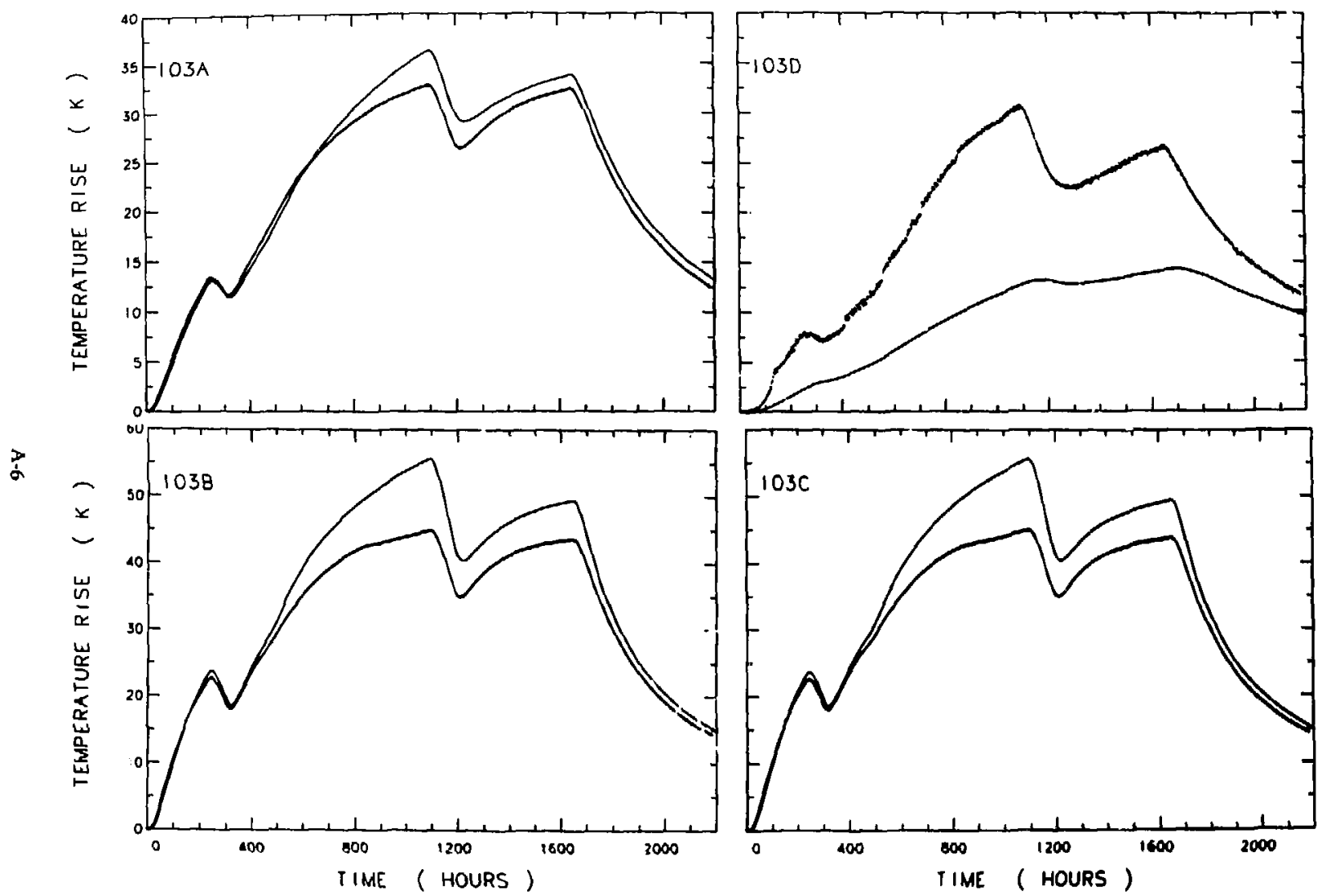

Figure A-4. Calculated and measured temperature histories for test using heater H-1, borehole I-03. Alphabetic code: are A $=$ below heater, $B$ and $C=$ at heater midplane, and $D=$ above heater midplane. 

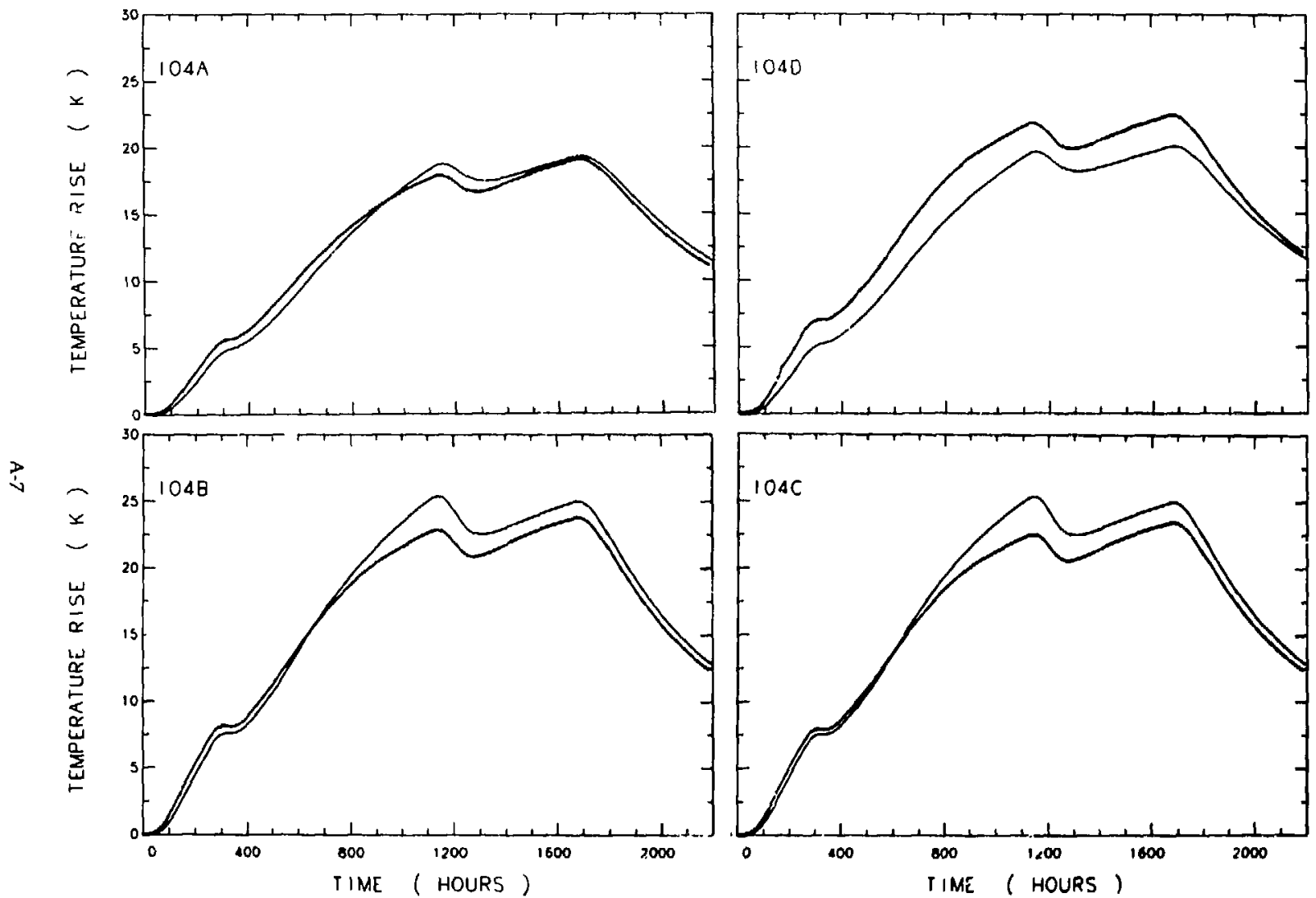

Figure A-5. Calculated and measured temperature histories for teat using heater H-1, borehole I-04. Alphabetic codes are A $\Rightarrow$ below heater, $B$ and $C=$ al heater midplane, and $D=$ above heater midplane. 

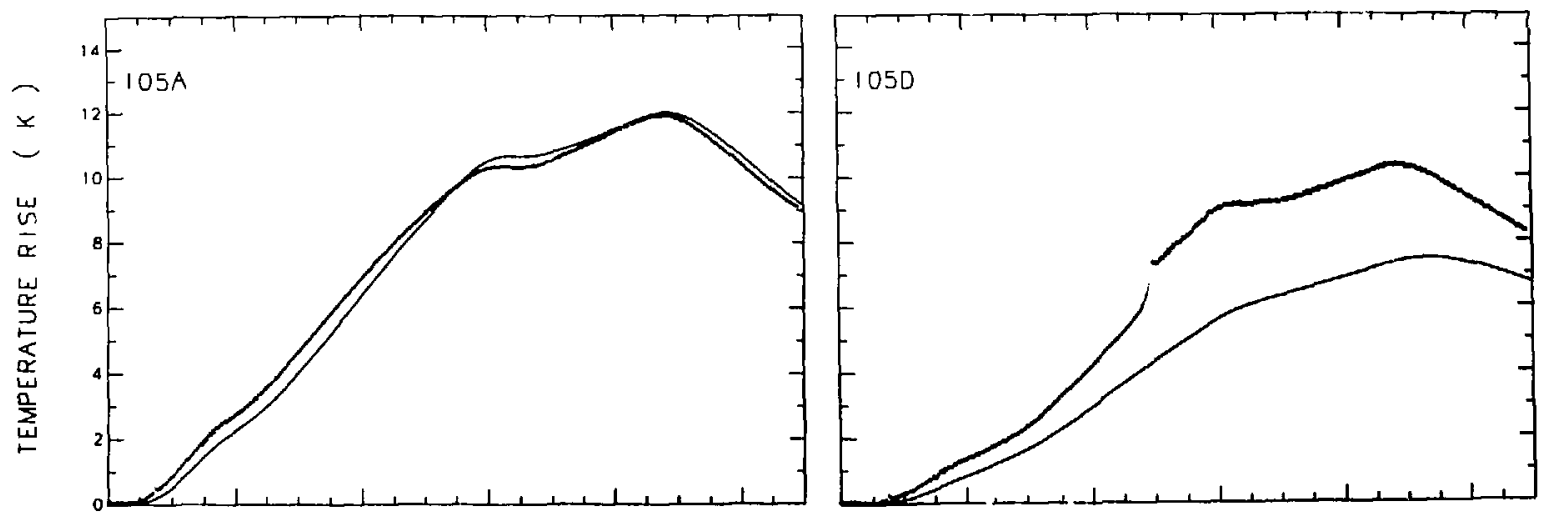

$\underset{\infty}{\infty}$
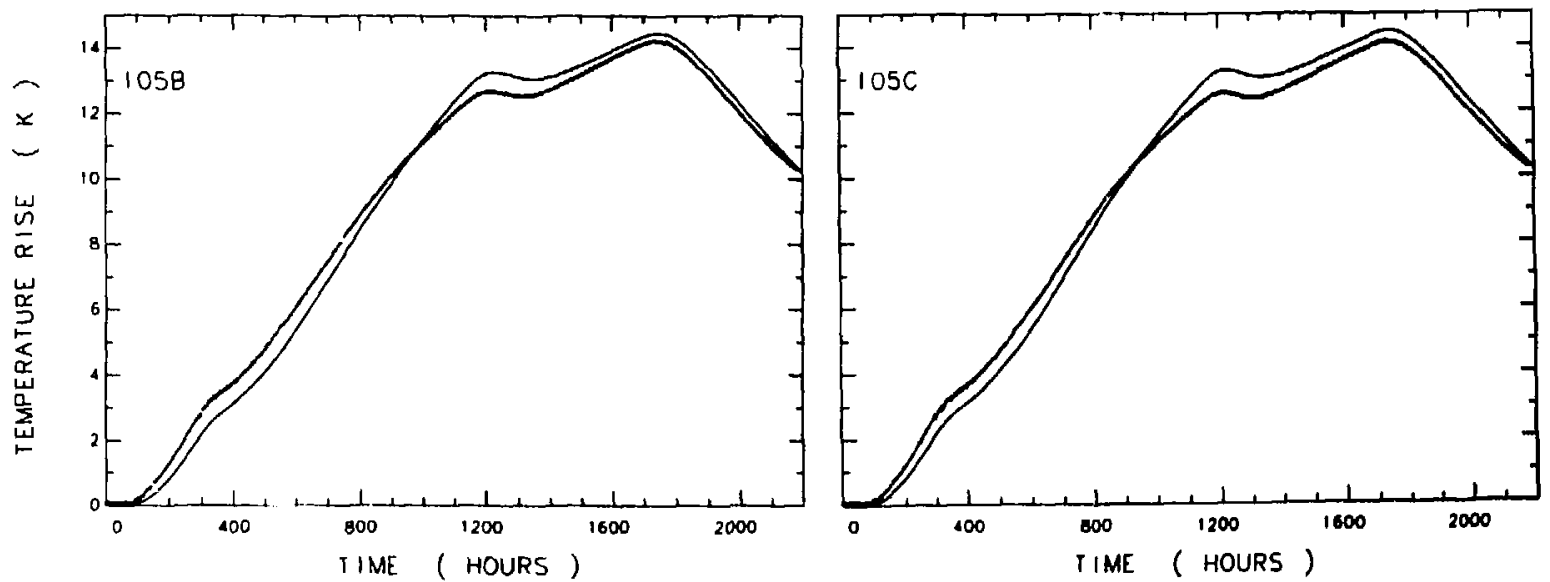

Figure A-6. Calculated and measured temperature histories for test using heater $H-1$, bosehole I-05. Alphabetic codes are $A \approx$ below heater, $B$ and $C=$ dt heater midplani, and $D=$ above heater midplane. 

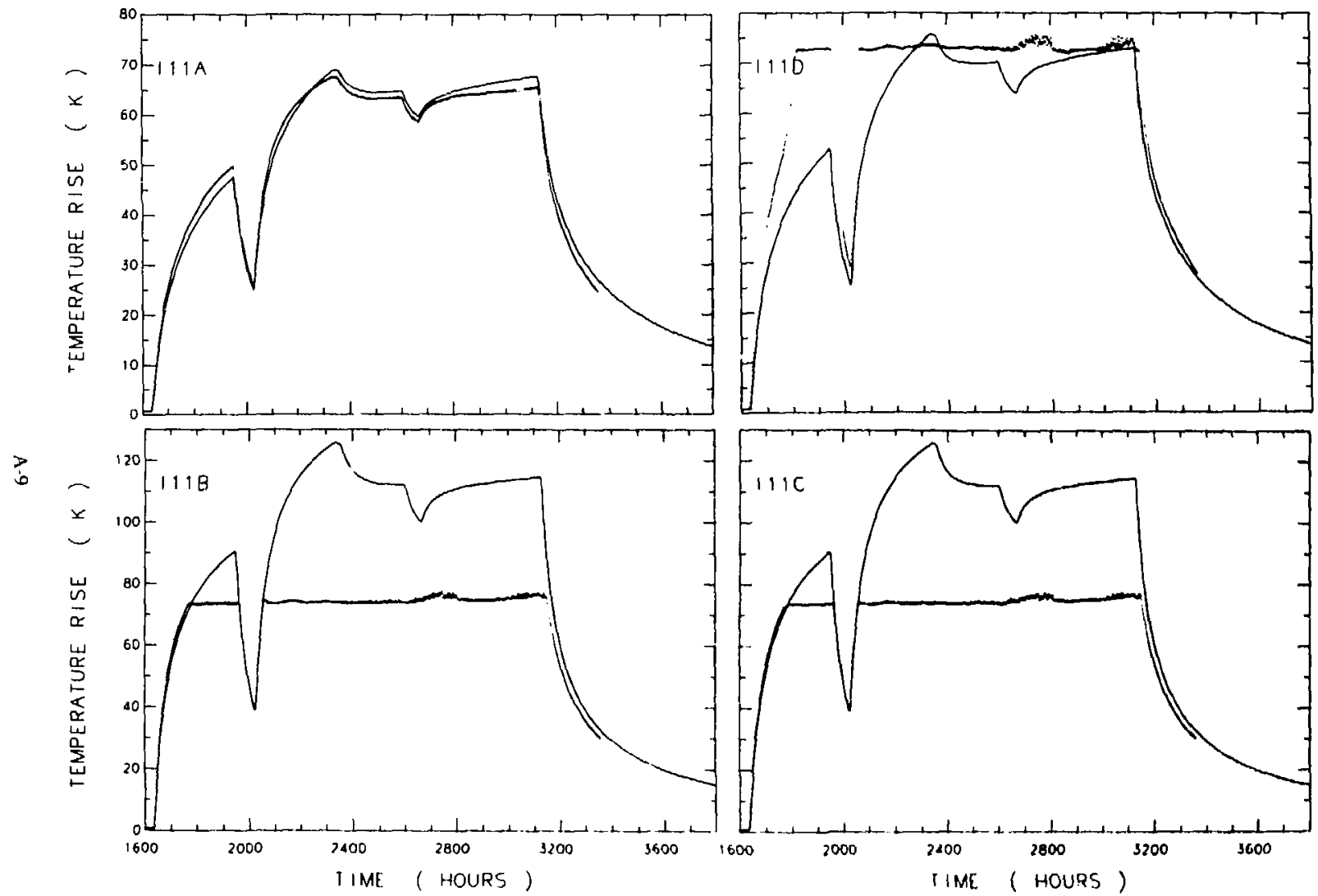

Figure A-7. Calculated and measured temperature histories for test using heater H-2, borehole l-11. Alphabetic codes are $A$ - below heater, $B$ and $C$. at heater midplane, and $D$ - above heater midplane. 

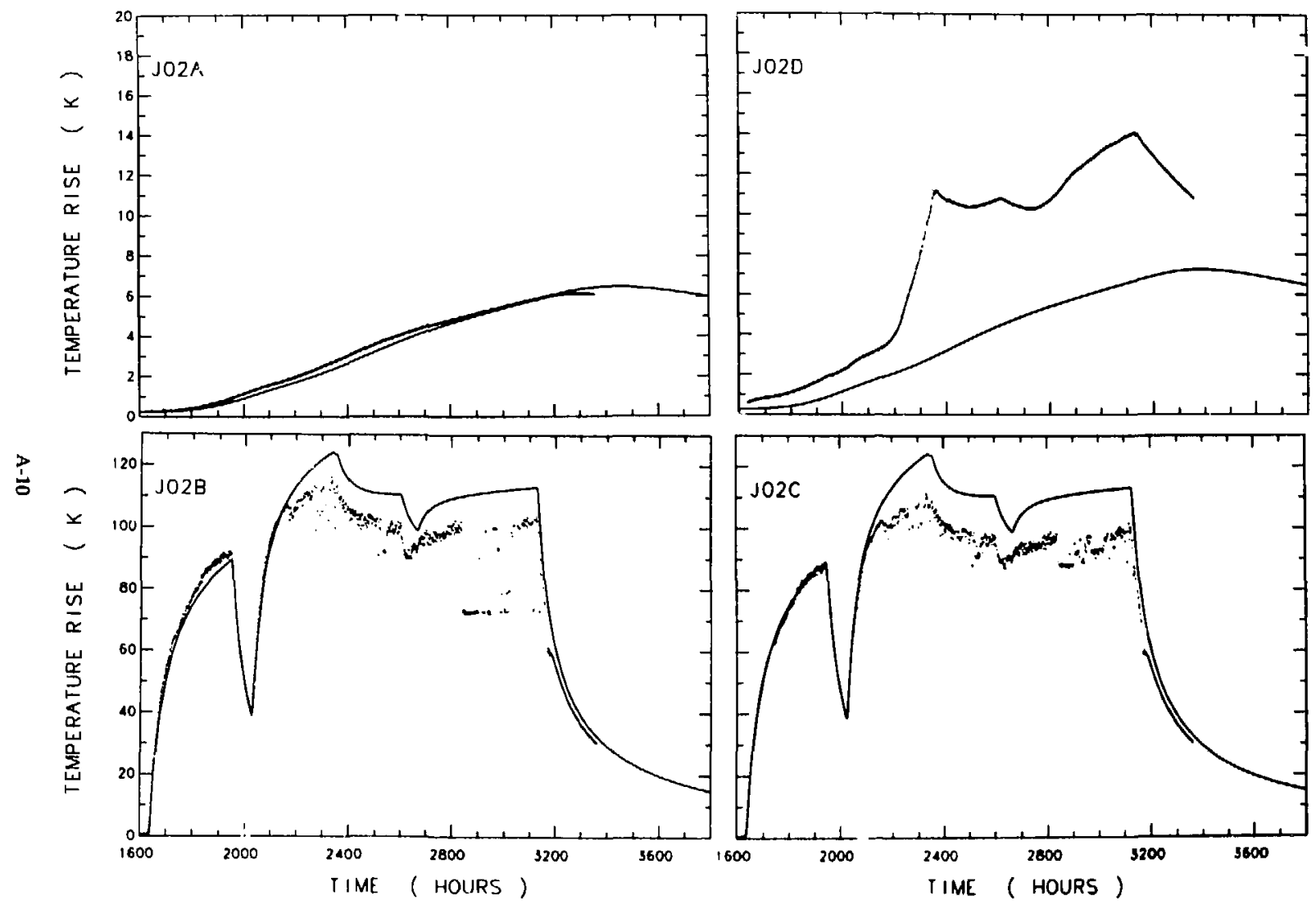

Figure A-8. Calculated and measured temperature histories for test using heater H-2, borehole J-02. Alphabetic codes are A * below heater, $B$ and $C=$ at heater midplane, and $D=$ above heater midplane. 

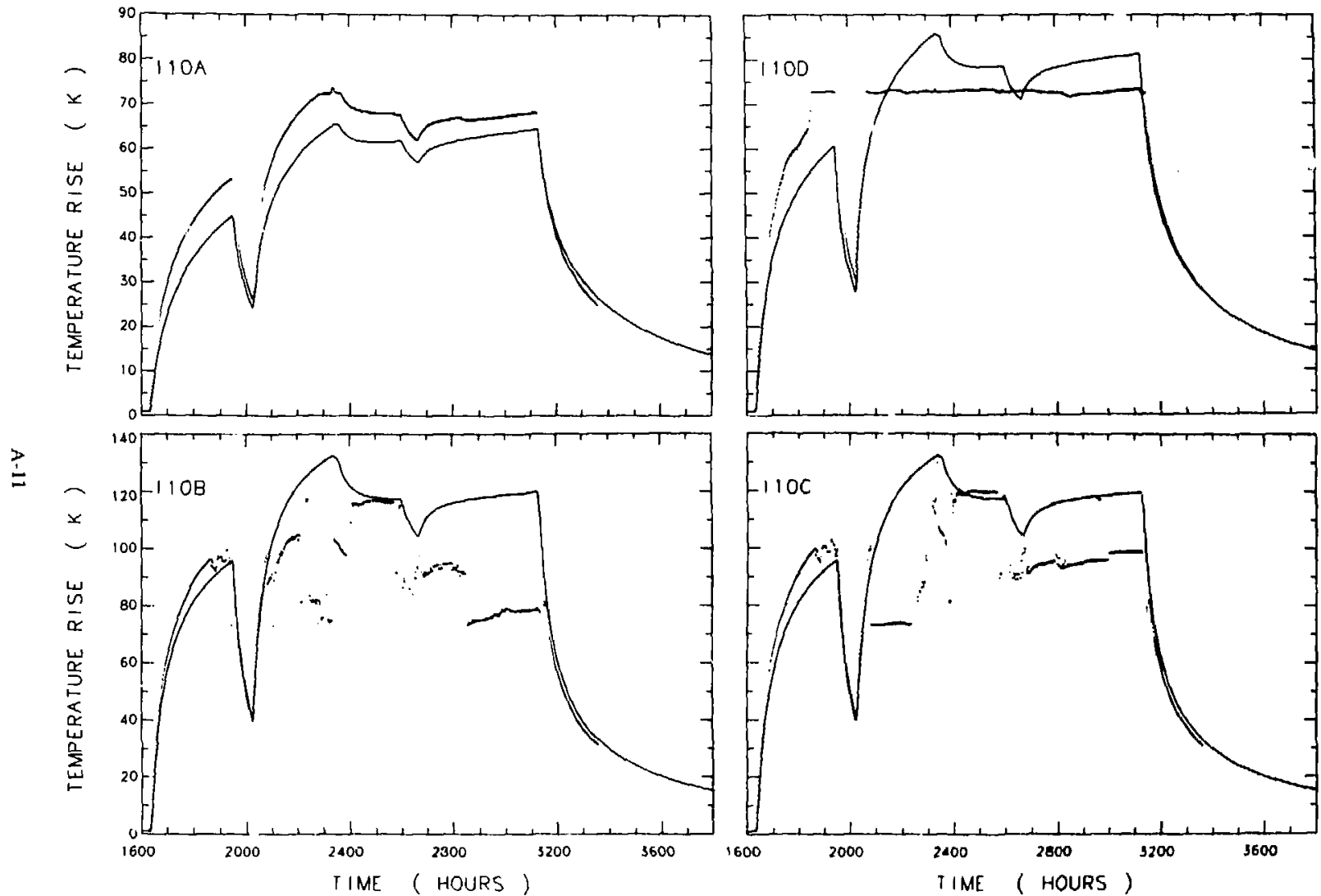

Figure A.9. Calculated and measured temperature histories for test using heater H-2, borehole I lo. Alphabetic codes are A :- below heater, $B$ and $C=$ at heater midplane, and $D=$ above heater midplane. 


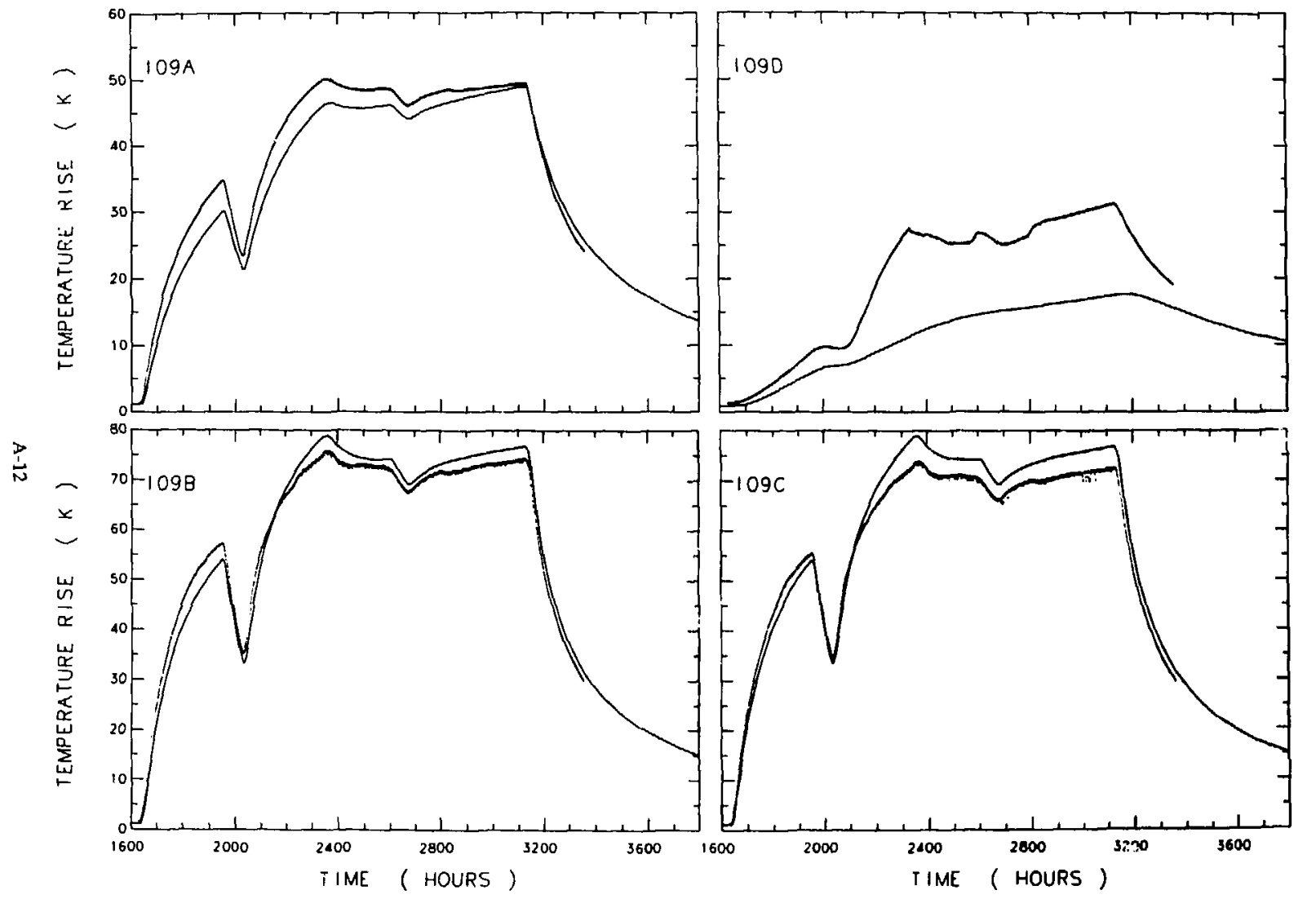

Figure A-10. Calculated and measured temperature histories for test using heater H-2, borehole I-09, Alphabetic codes are A = below heater, $B$ and $C=$ at heater midplane, and $D=$ above heater midplane. 

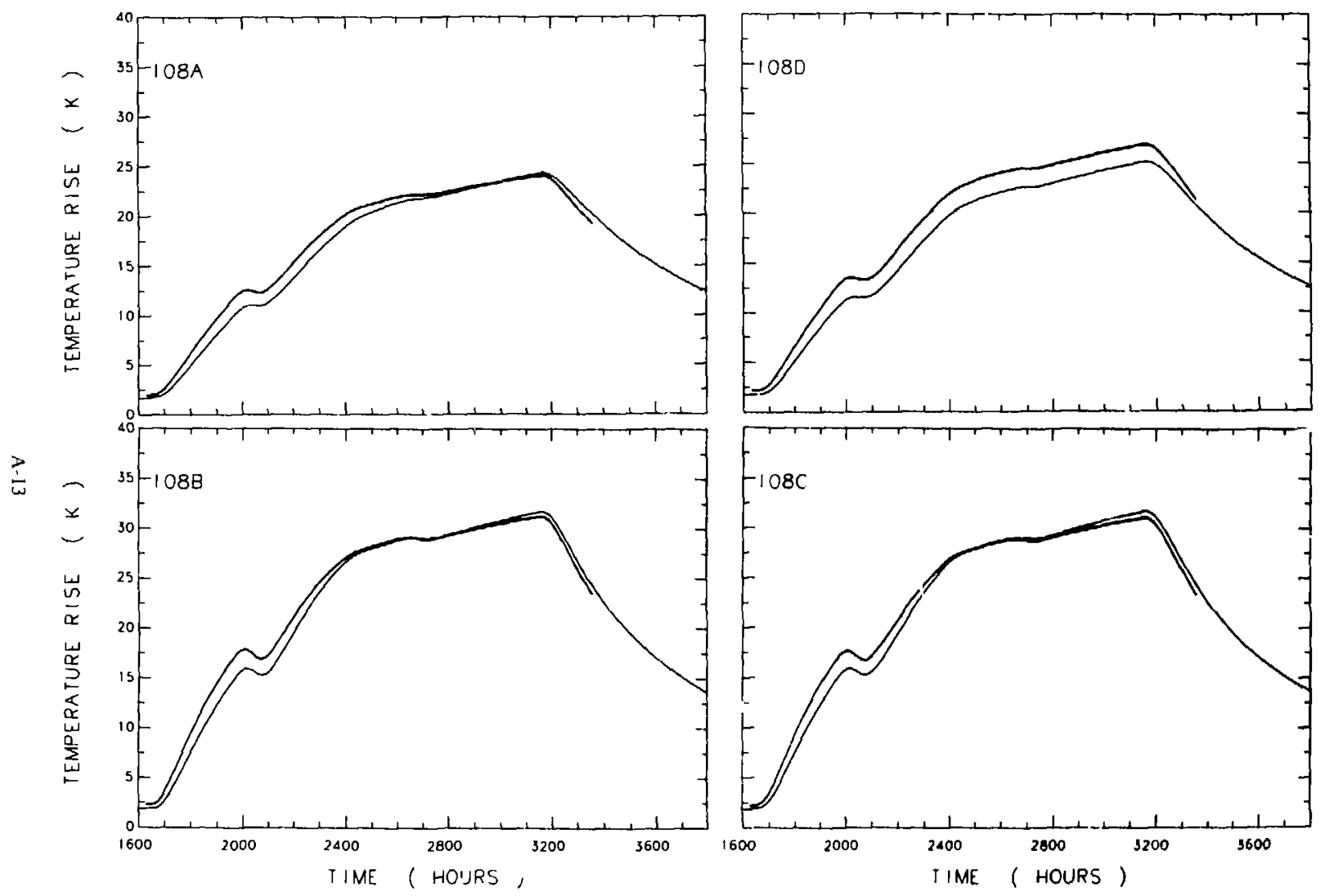

Figure A-11. Calculated and measured temperature histories for test using heater $\mathrm{H}-2$, borehole I-08. Alphabetic codes are A $=$ below heater, $B$ and $C$ = at heater midplane, and $D$-: above heater miriplane. 

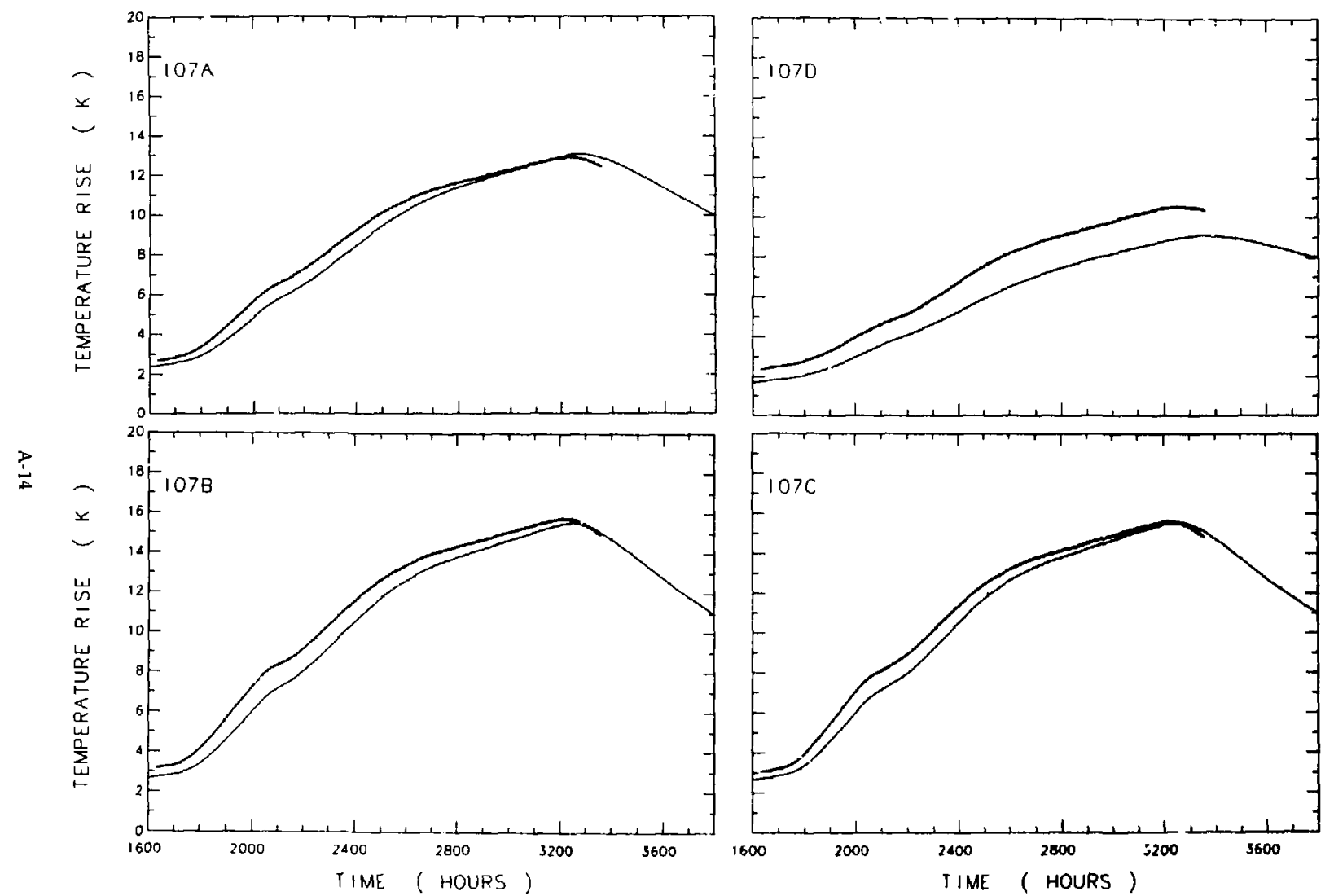

Figure A-12. Caliulated and measured temperature histories for test using heater H-2, borehole I-07. Alphabetic codes are A $=$ below heater, $B$ and $C=$ at heater midplane, and $D=$ above heater midplane. 


\section{Appendix B \\ Permeability Test Data and Analysis}

B-1-2 

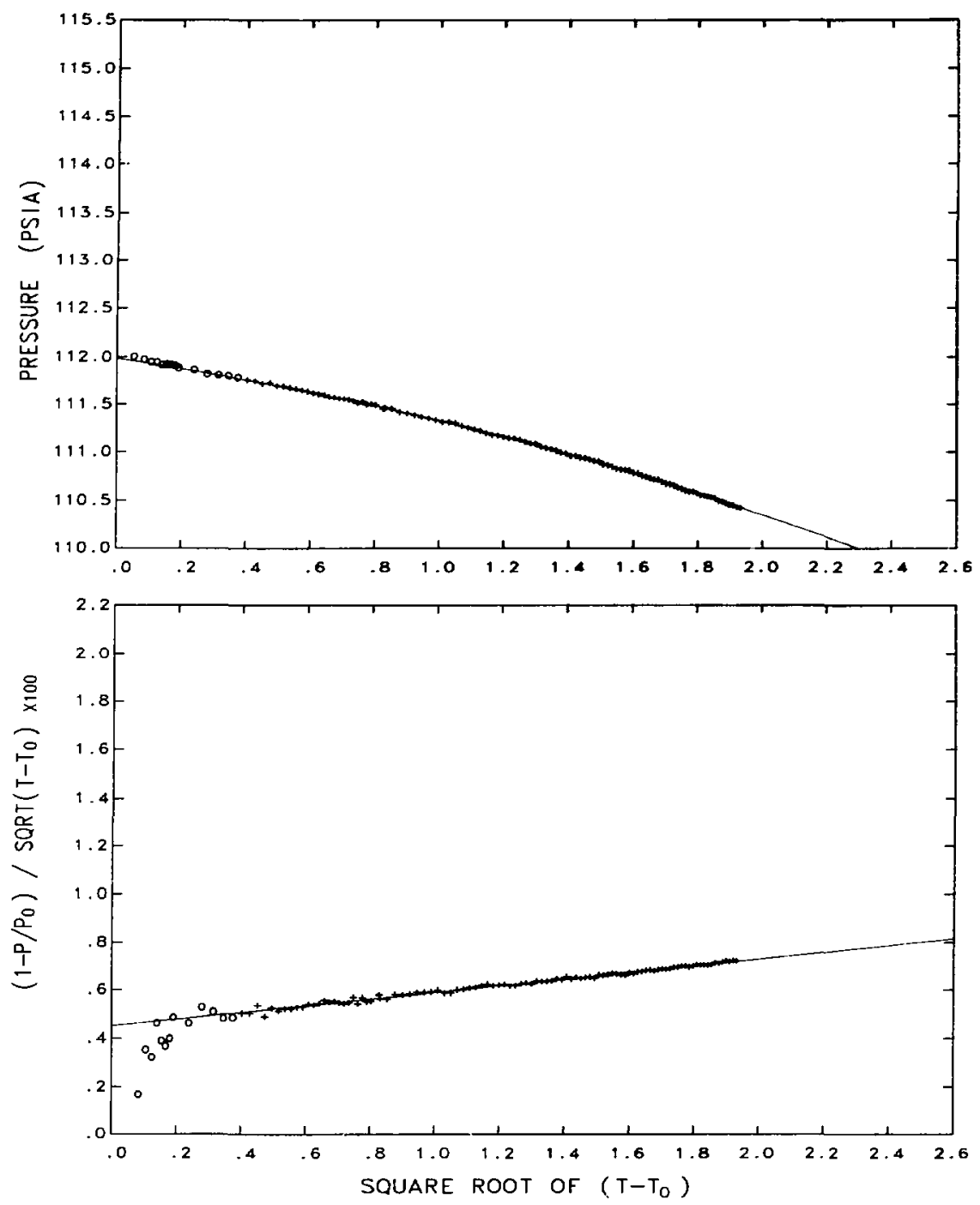

FIGURE B-1. PERMEABILITY TEST M, HOLE J-02. $T_{0}=103.69$ DAYS, AVERAGE TEMPERATURE $=32.3 \mathrm{C}$, 99 OF 113 DATA POINTS USED, RESIDUAL $=.007$. PERMEABILITY $=.40$ ND, POROSITY $=.0028$. 

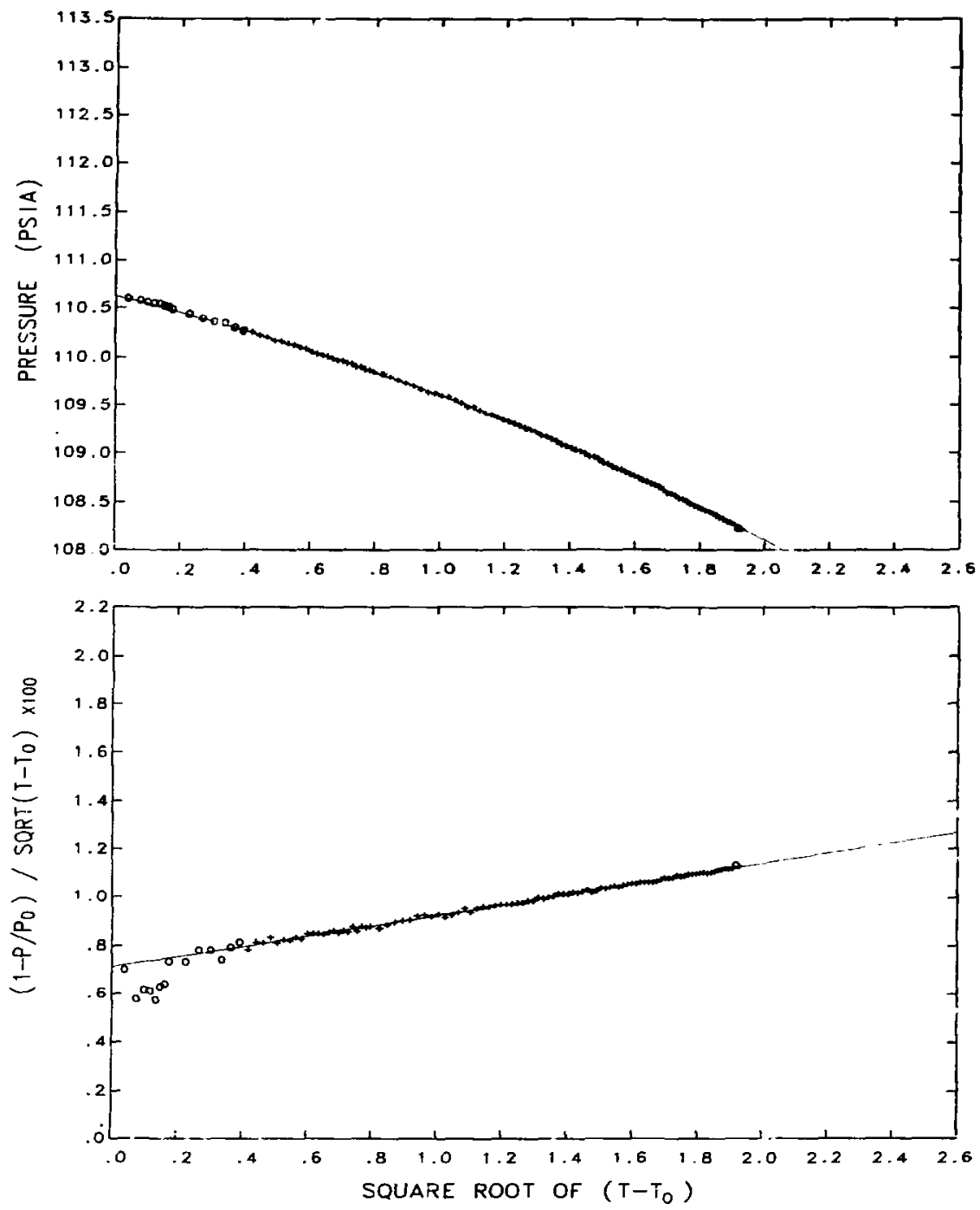

FIGURE B-2. PERMEABILITY TEST $M$, HOLE 1-09, $T_{0}=103.70$ DAYS, AVERAGE TEMPERATURE $=32.4 \mathrm{C}$, 97 OF 112 DATA POINTS USED, RESIDUAL $=.007$, PERMEABILITY $=.62 \mathrm{ND}$, POROSITY $=.0047$. 

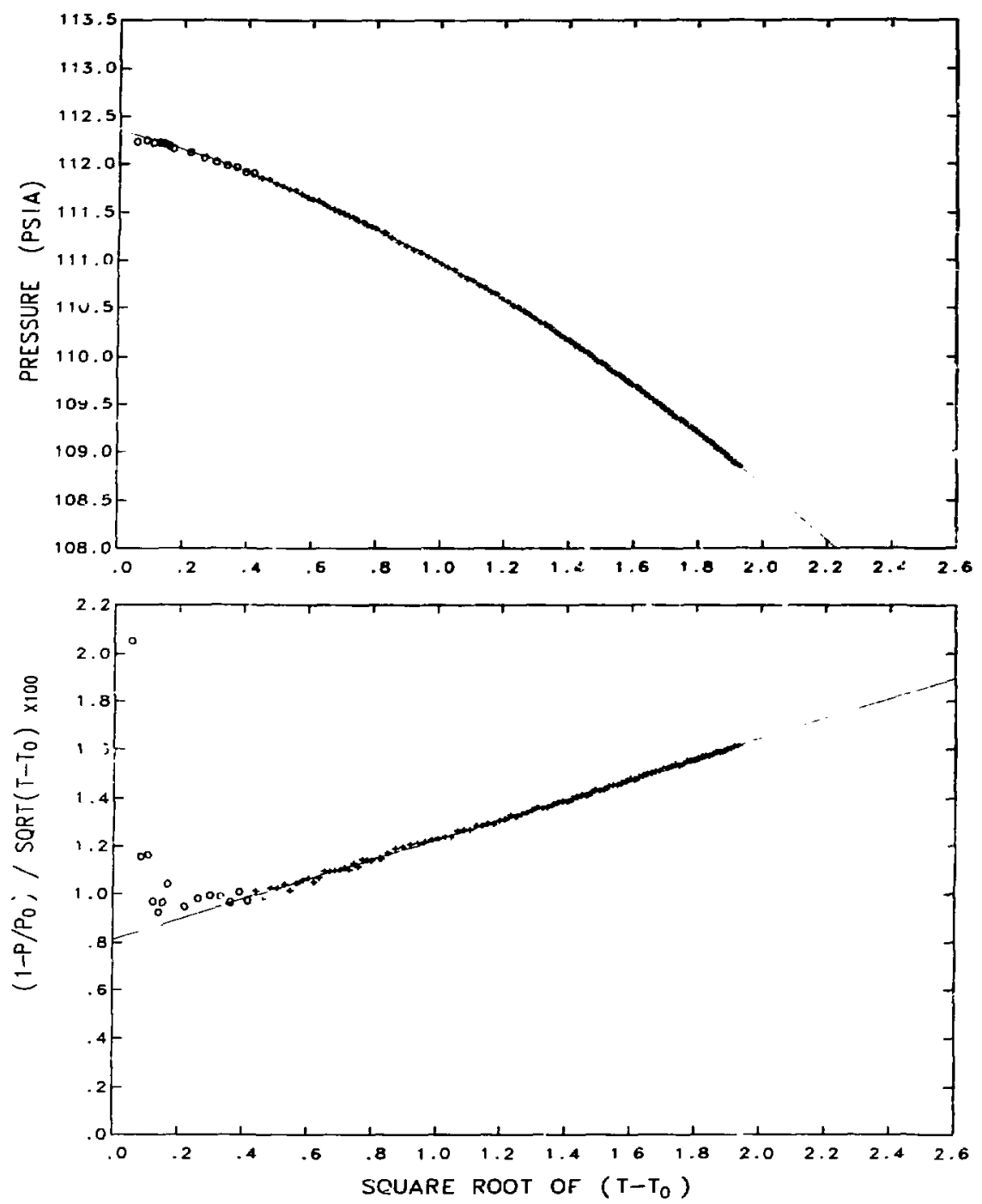

FIGURE B-3. PERMEABILITY TEST $M$, HOLE $1-10$. $\mathrm{T}_{0}=103.70$ DAYS, AVERAGE TEMPERATURE $=32.4 \mathrm{C}$. 97 OF 111 DATA POINTS USED, RESIDUAL $=.007$. PERMEABILITY $=1.19$ ND, POROSITY $=.0031$. 

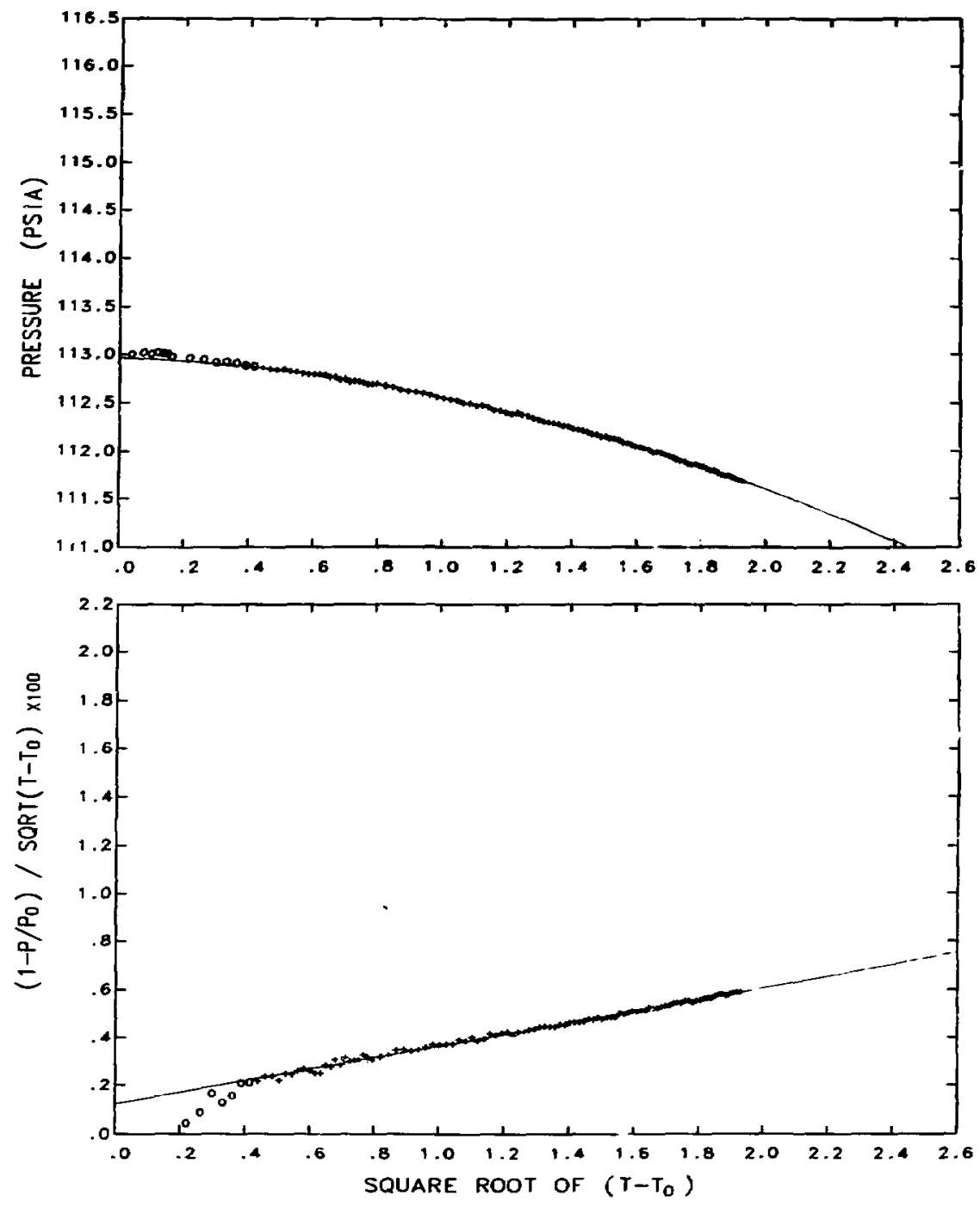

FIGURE B-4. PERMEABILITY TEST M. HOLE $1-11$. $T_{0}=103.70$ DAYS, AVERAGE TEMPERATURE $=32.3 \mathrm{C}$, 97 OF 111 DATA POINTS USED, RESIDUAL $=.009$. PERMEABILITY $=.69 \mathrm{ND}$, POROSITY $=.0001$. 

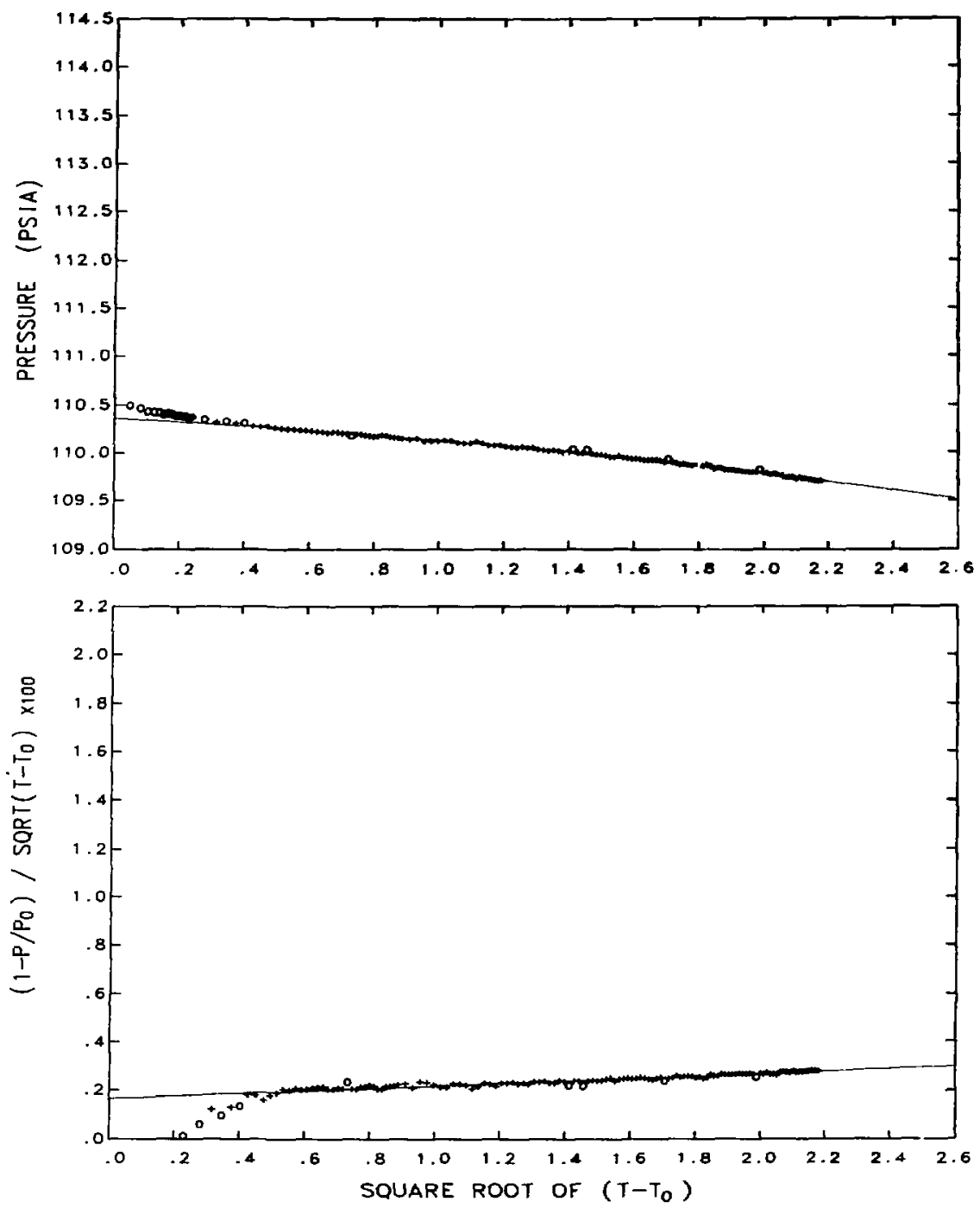

FIGURE B-5. PERMEABILITY TEST N, HOLE J-02, $T_{0}=117.59$ DAYS, AVERAGE TEMPERATURE $=51.2 \mathrm{C}$, 122 OF 144 DATA POINTS USED. RESIDUAL $=.009$. PERMEABILITY $=.15 \mathrm{ND}$, POROSITY $=.0010$. 

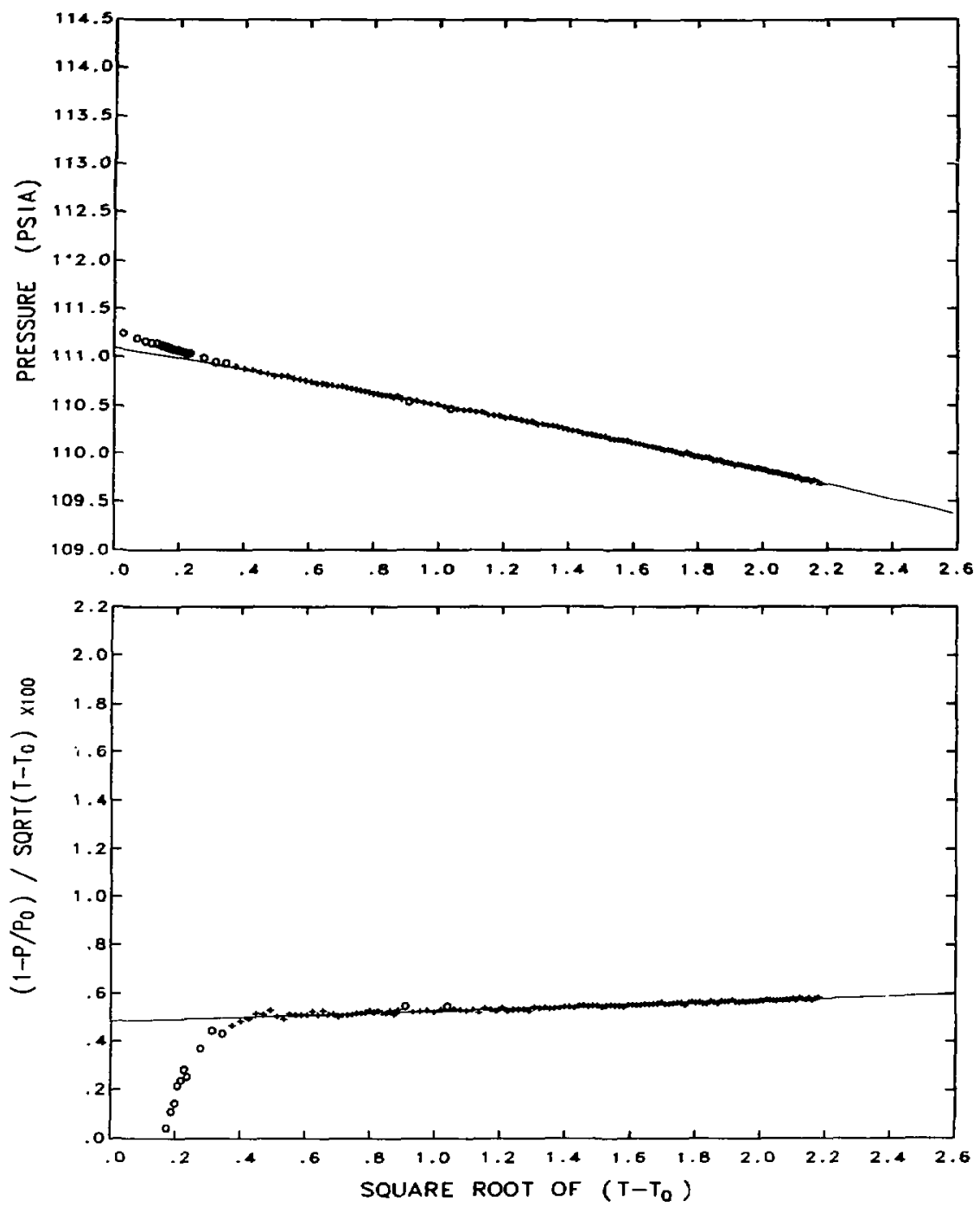

FIGURE B-6. PERMEABILITY TEST $N$, HOLE I-O9, $T_{0}=117.59$ DAYS, AVERAGE TEMPERATURE $=43.6 \mathrm{C}$, 125 OF 144 DATA POINTS USED, RESIDUAL $=.007$. PERMEABILITY $=.13 \mathrm{ND}$, POROSITY $=.0103$. 

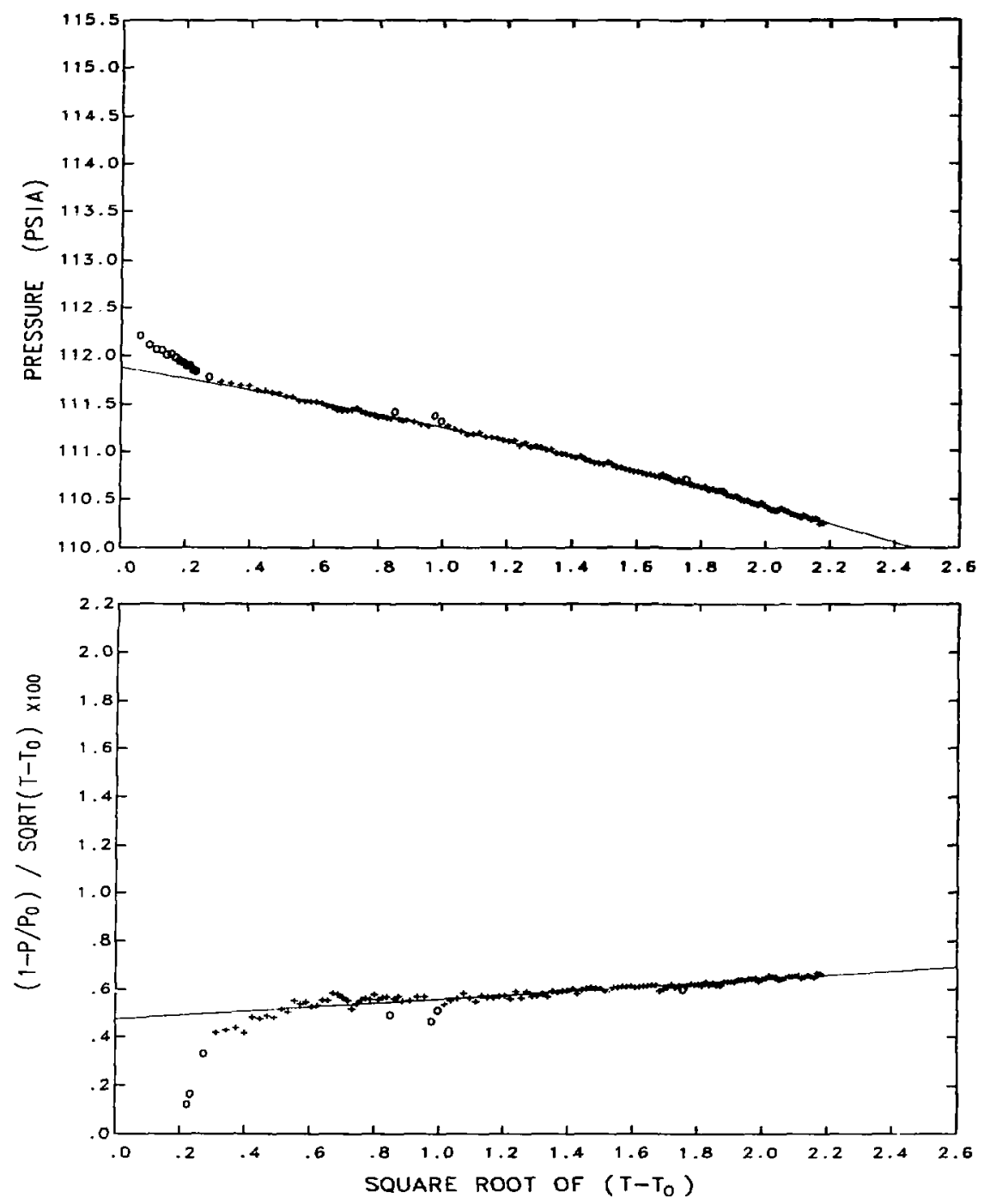

FIGURE B-7. PERMEABILITY TEST N, HOLE 1-10, $T_{0}=117.59$ DAYS, AVERAGE TEMPERATURE $=53.4 \mathrm{C}$. 125 OF 143 DATA POINTS USED. RESIDUAL $=.017$. PERMEABILITY $=.24 \mathrm{ND}$, POROSITY $=.0053$. 

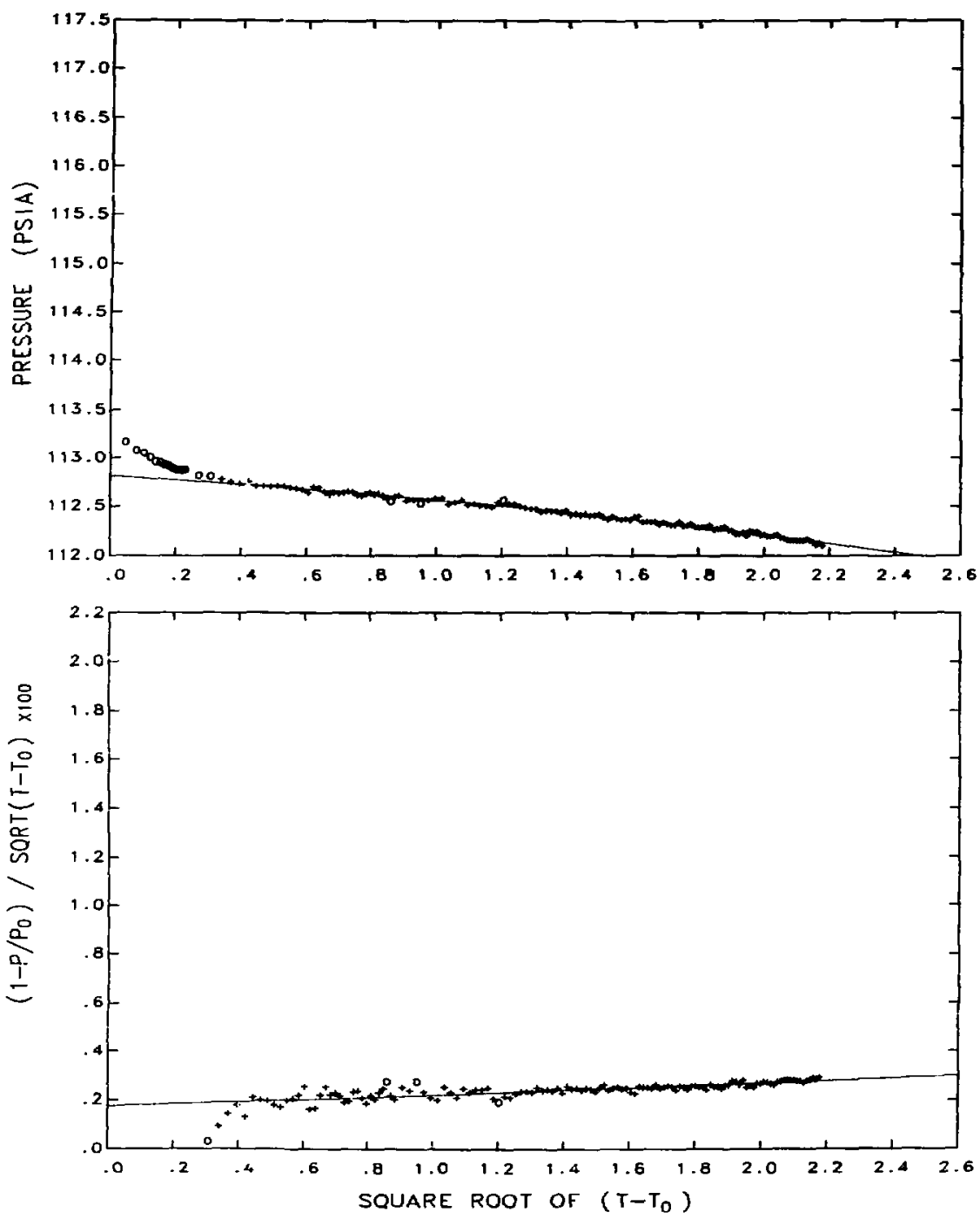

FIGURE B-8. PERMEABILITY TEST $N$, HOLE $1-11$. $T_{0}=117.59$ DAYS, AVERAGE TEMPERATURE $=51.3 \mathrm{C}$, 125 OF 143 DATA POINTS USED, RESIDUAL $=.018$. PERMEABILITY $=.13$ ND, POROSITY $=.0012$. 

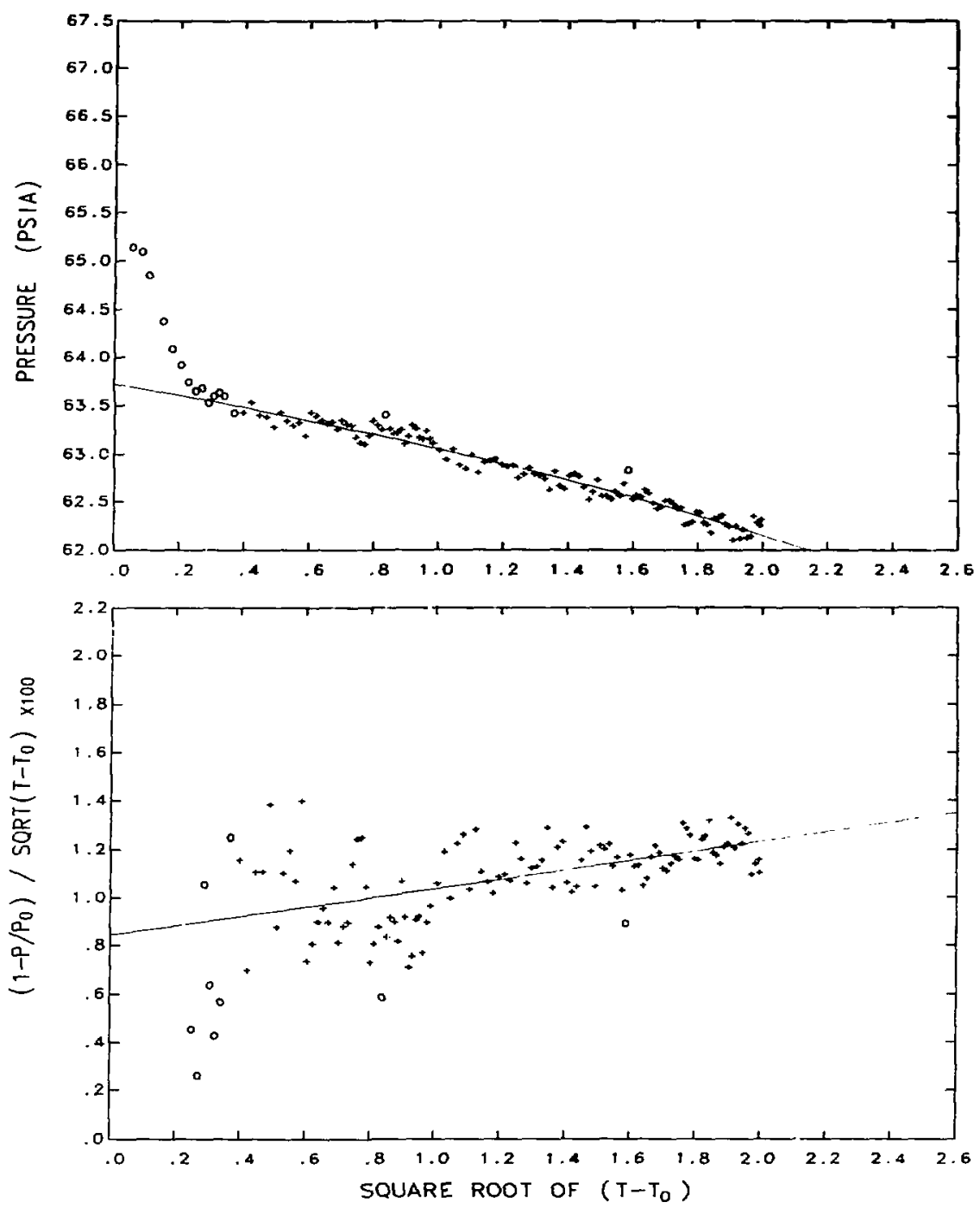

FIGURE B-9. PERMEABILITY TEST O. HOLE H-O2, $T_{0}=138.36$ DAYS, AVERAGE TEMPERATURE $=419.3 \mathrm{C}$. 111 OF 127 DATA POINTS USED, RESIDUAL $=.082$. PERMEABILITY $=1.09$ ND. POROSIT $=.0071$. 

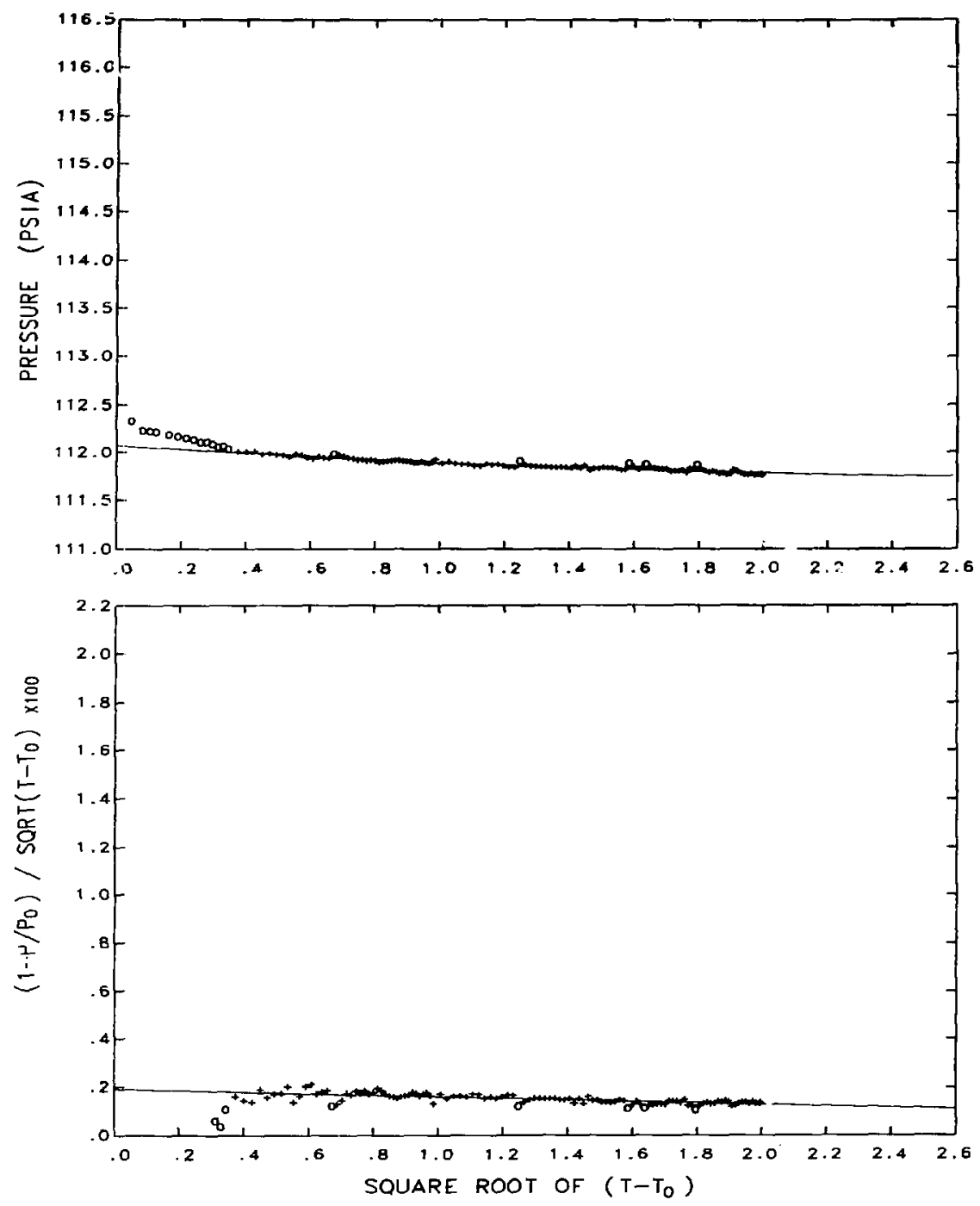

FIGURE B-10. PERMEABILITY TEST O, HOLE J-02 . $T_{0}=138.36$ DAYS, AVERAGE TEMPERATURE $=74.3 \mathrm{c}$, 109 OF 128 DATA POINTS USED. RESIDUAL $=.015$.

PERMEABILITY $=-.09$ ND. POROSITY $=-.0024$ 

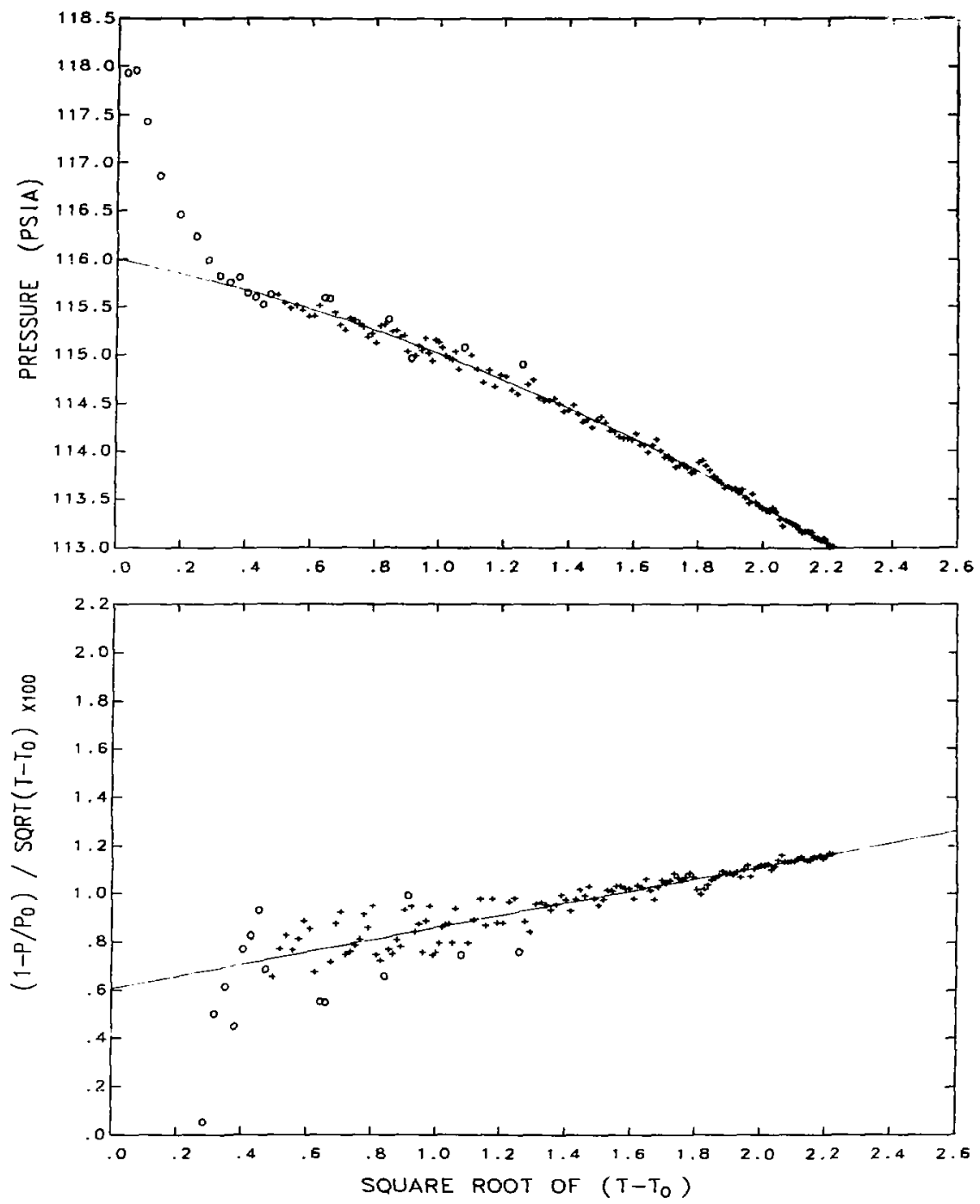

FIGURE B-11. PERMEABILITY TEST P, HOLE 1-O9, $T_{0}=151.42$ DAYS, AVERAGE TEMPERATURE $=70.9 \mathrm{C}$. 128 OF 148 DATA POINTS USED, RESIDUAL $=.060$. PERMI.ABILITY $=.70 \mathrm{ND}$, POROSITY $=.0029$. 

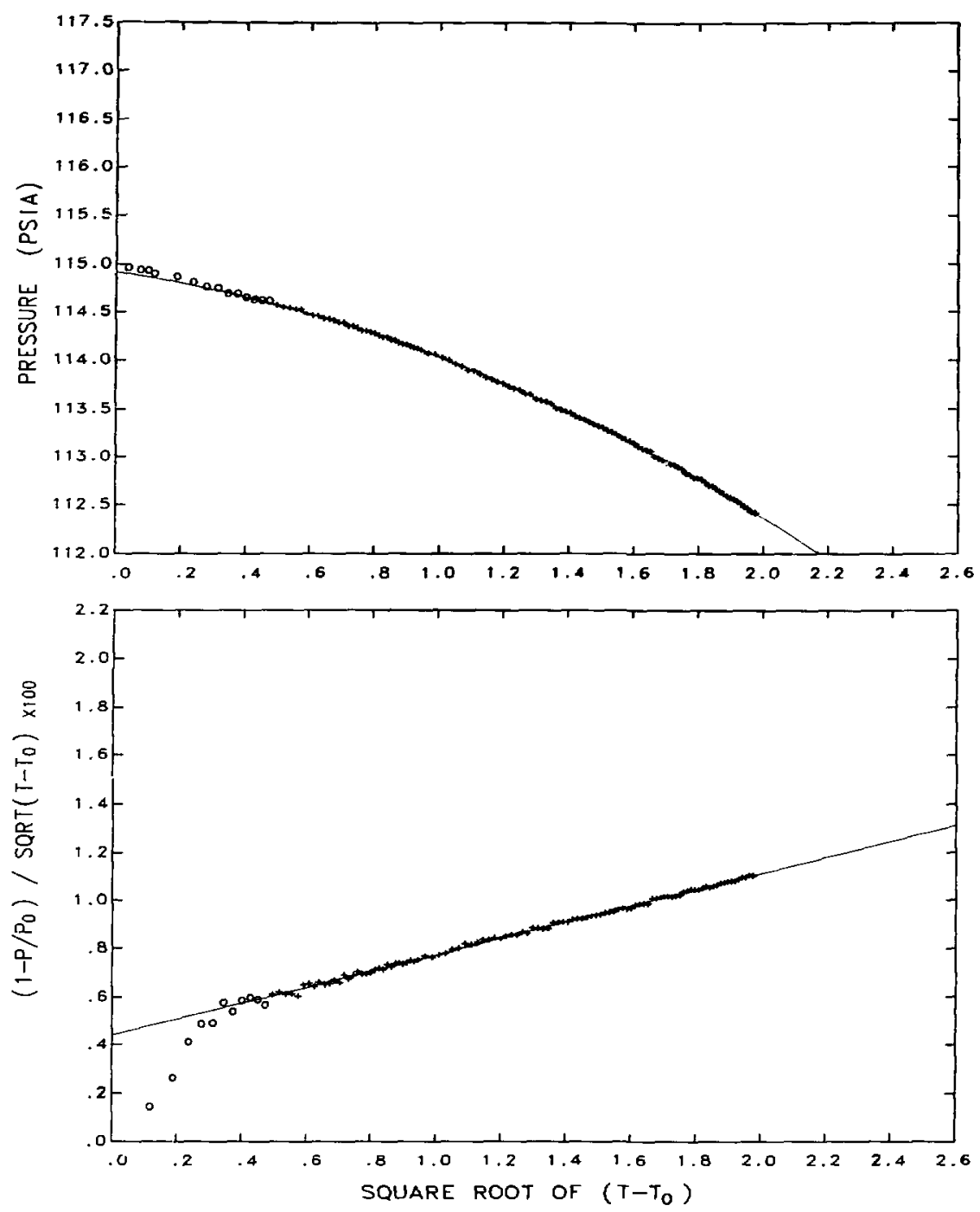

FIGURE B-12. PERMEABILITY TEST Q, HOLE 1-09. $\mathrm{T}_{0}=159.45$ DAYS, AVERAGE TEMPERATURE $=46.8 \mathrm{C}$, 105 OF 119 DATA POINTS USED. RESIDUAL $=.009$. PERMEABILITY $=.93$ ND, POROSITY $=.0011$. 

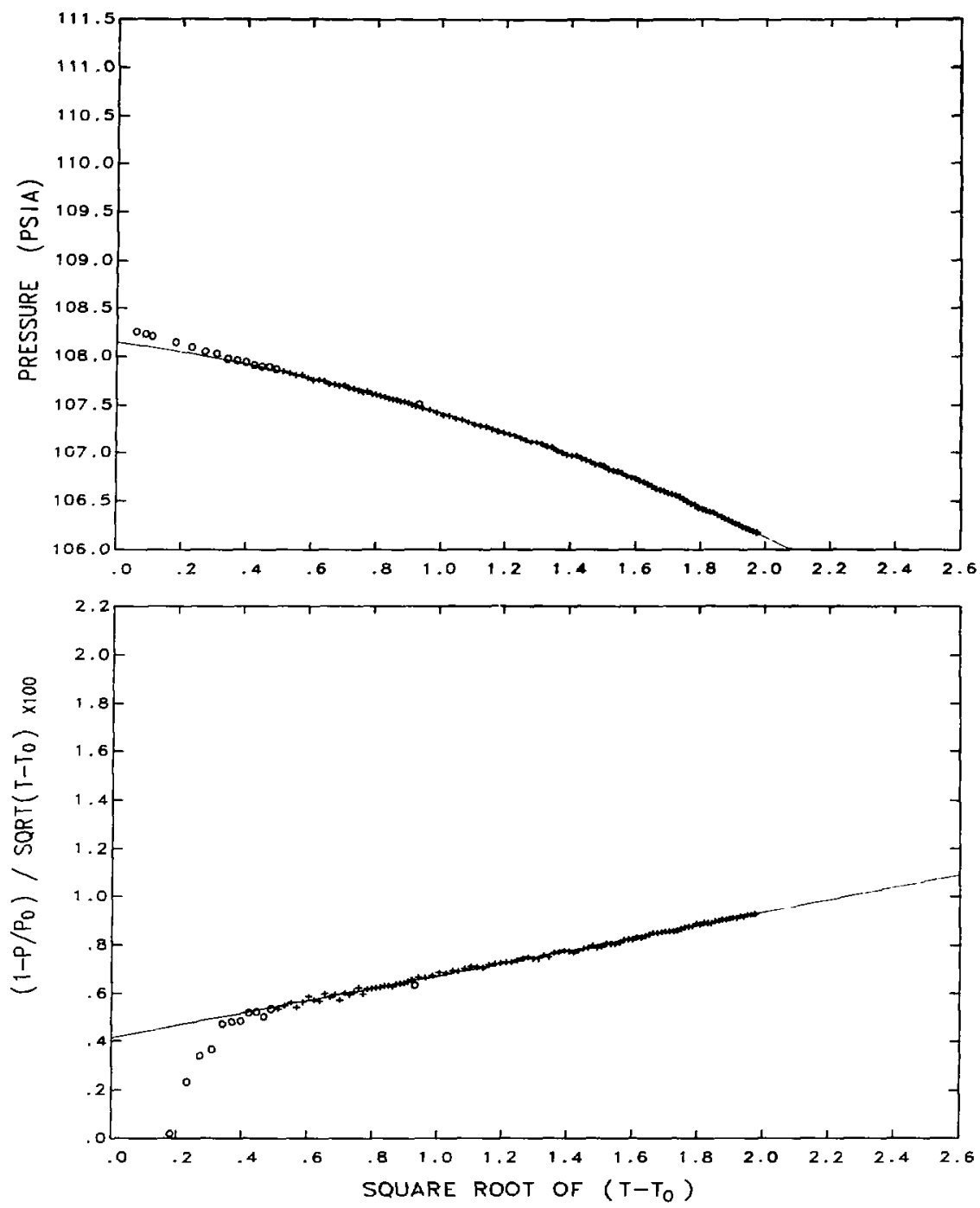

FIGURE B-13. PERMEABILITY TEST Q, HOLE $1-10$, $T_{0}=159.45$ DAYS, AVERAGE TEMPERATURE $=47.7 \mathrm{C}$, 103 OF 118 DATA POINTS USED. RESIDUAL $=.008$, PERMEABILITY $=.78$ ND, POROSITY $=.0013$. 

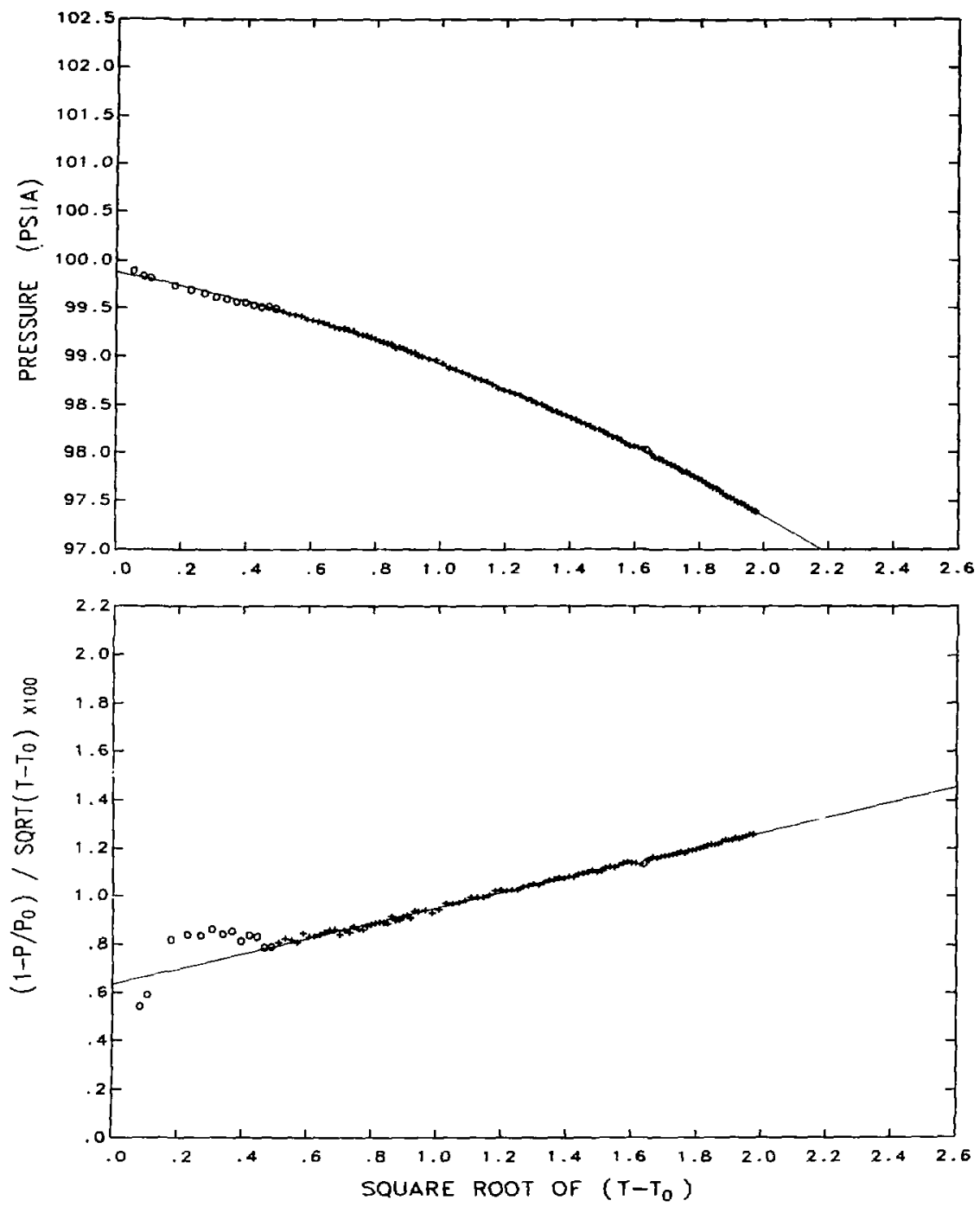

FIGURE B-14. PERMEABILITY TEST Q, HOLE I-11, $T_{0}=159.45$ DAYS, AVERAGE TEMPERATURE $=47.5 \mathrm{C}$, 103 OF 118 DATA POINTS USED, RESIDUAL $=.008$.

PERMEABILITY $=1.03$ ND, POROSITY $=.0025$. 

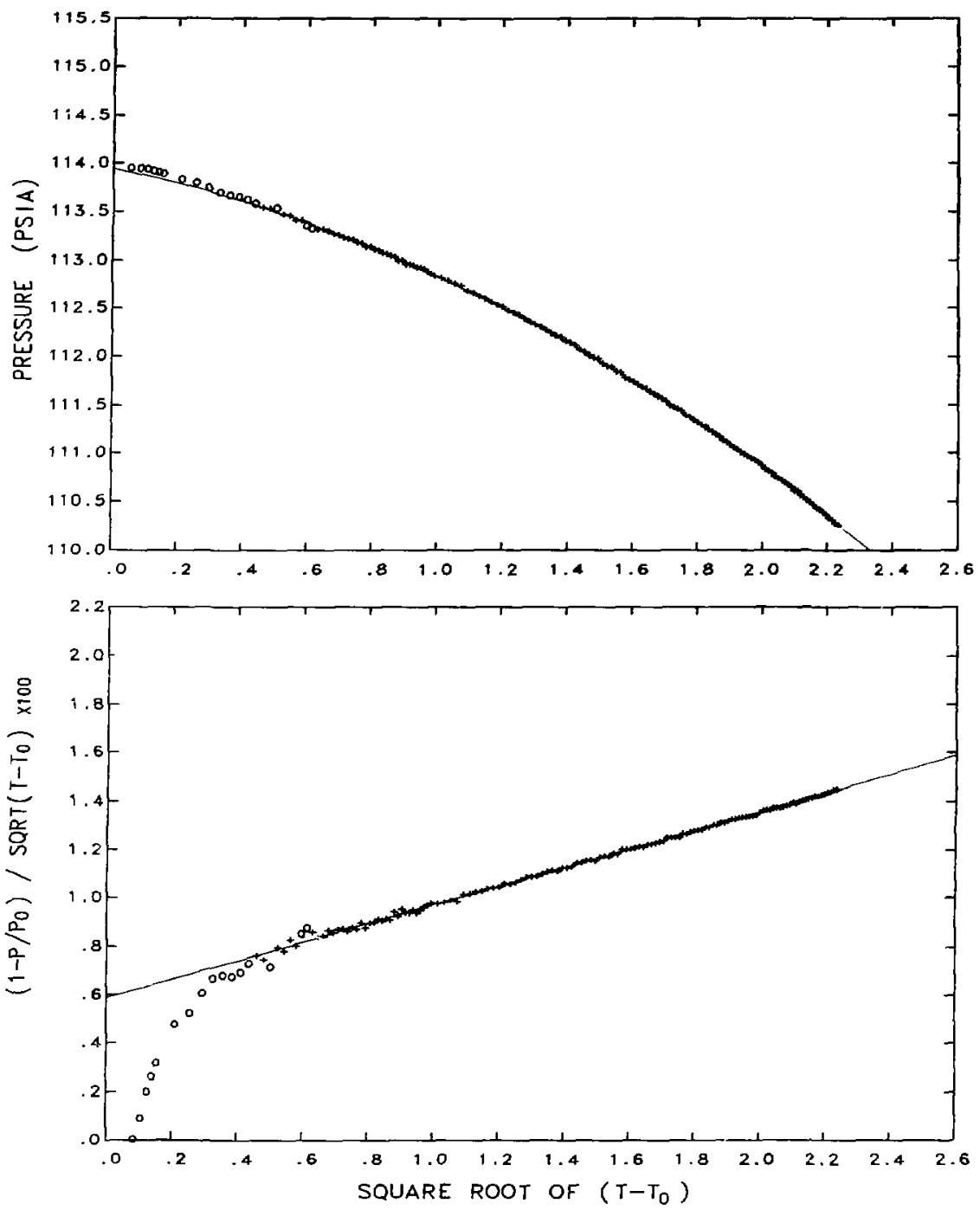

FIGURE B-15.

PERMEABILITY TEST R, HOLE I-O9. $T_{0}=172.35$ DAYS, AVERAGE TEMPERATURE $=36.4 \mathrm{C}$. 132 OF 149 DATA POINTS USED, RESIDUAL $=.008$. PERMEABILITY $=1.08$ ND, POROSITY $=.0018$. 

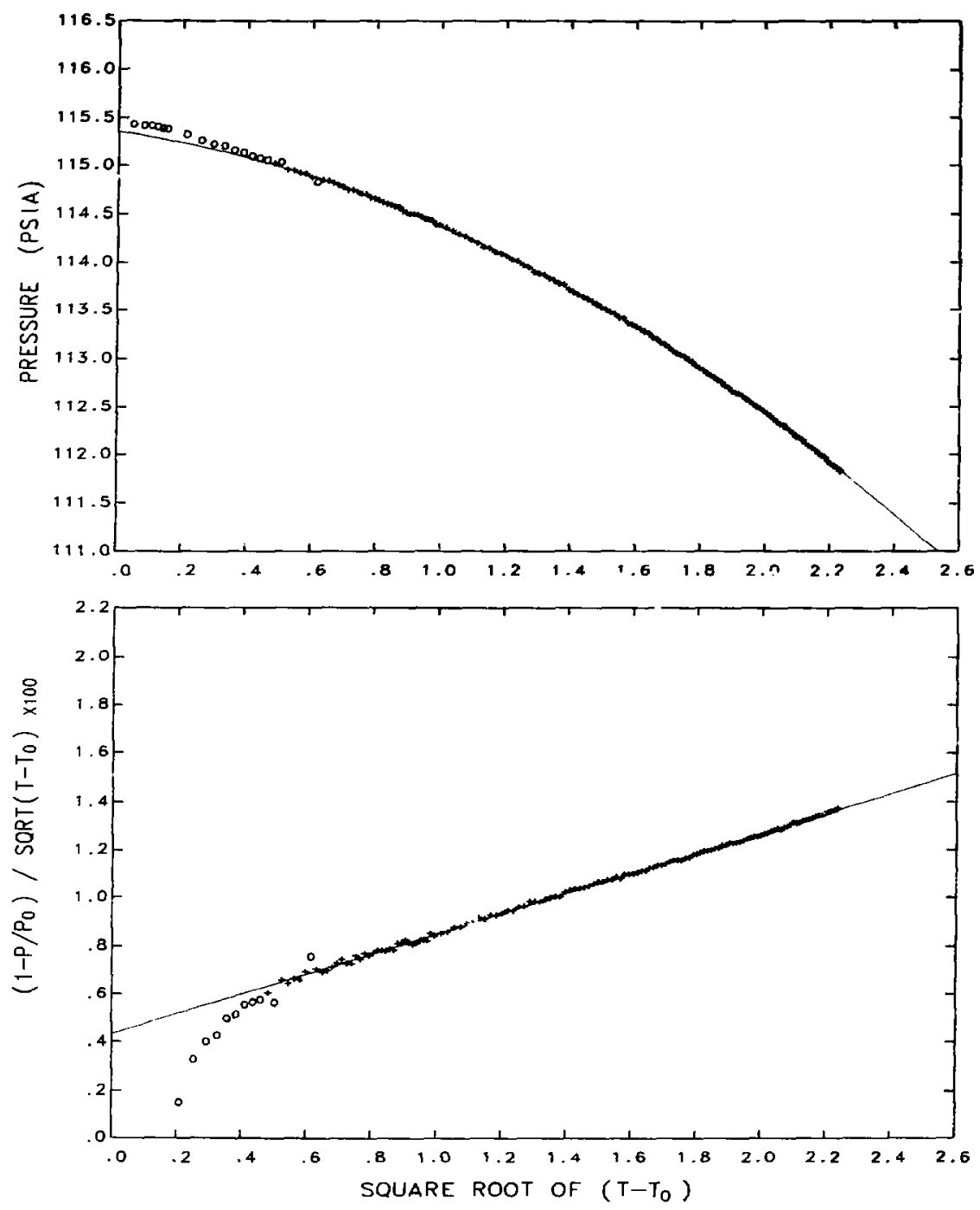

FIGURE $8-16$.

PERMEABILITY TEST R, HOLE I-10,

$\mathrm{T}_{0}=172.35$ DAYS, AVERAGE TEMPERATURE $=36.6 \mathrm{C}$, 132 OF 149 DATA POINTS USED, RESIDUAL $=.009$,

PERMEABILITY $=1.16 \mathrm{ND}$, POROSITY $=.0009$. 

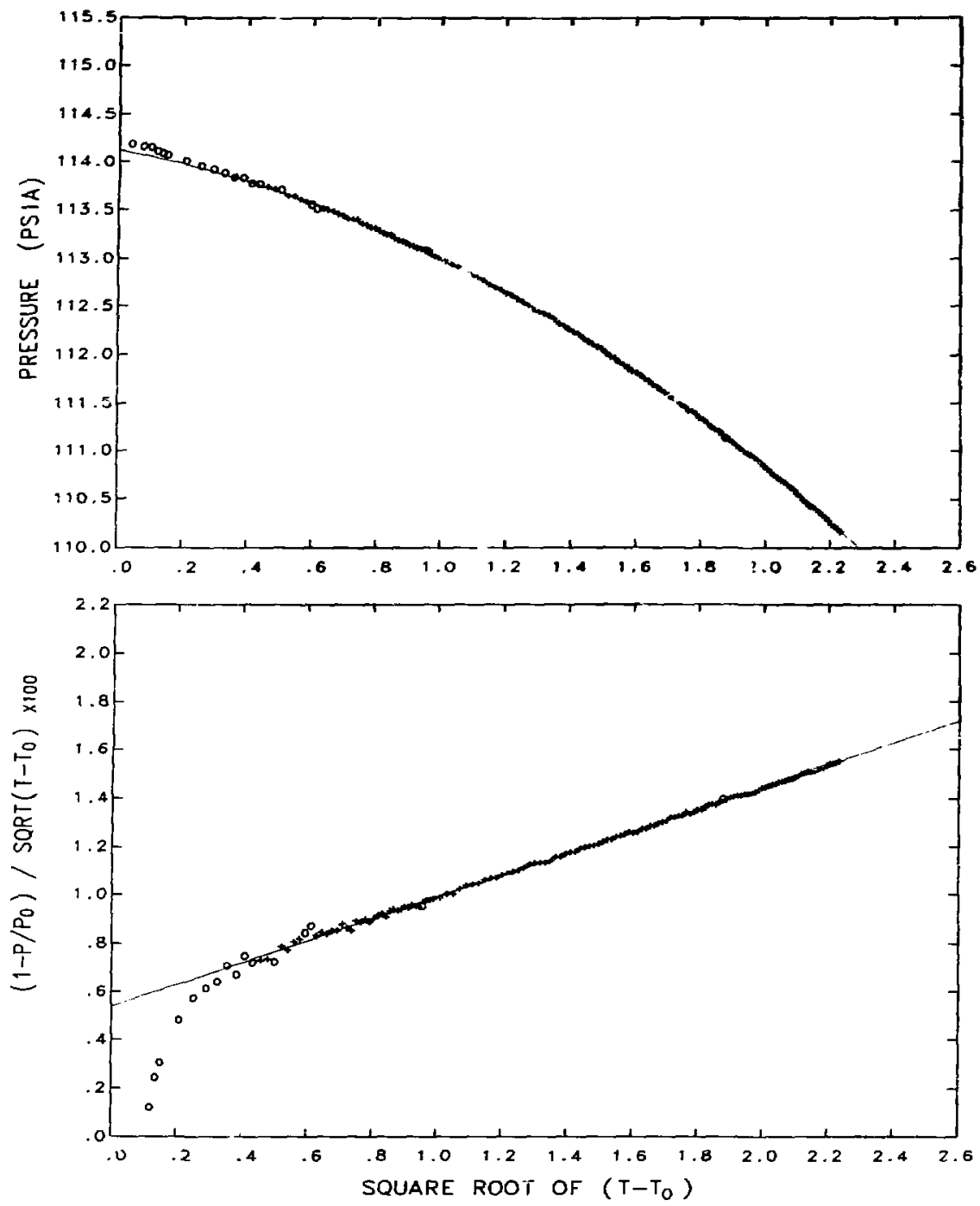

FIGURE B-17. PERMEABILITY TEST R, HOLE I-11. $T_{0}=172.35$ DAYS, AVERAGE TEMPERATURE $=36.5 \mathrm{C}$, 130 OF 149 DATA POINTS USED, RESIDUAL $=.007$. PERMEABILITY $=1.27$ ND, POROSITY $=$. CO13. 

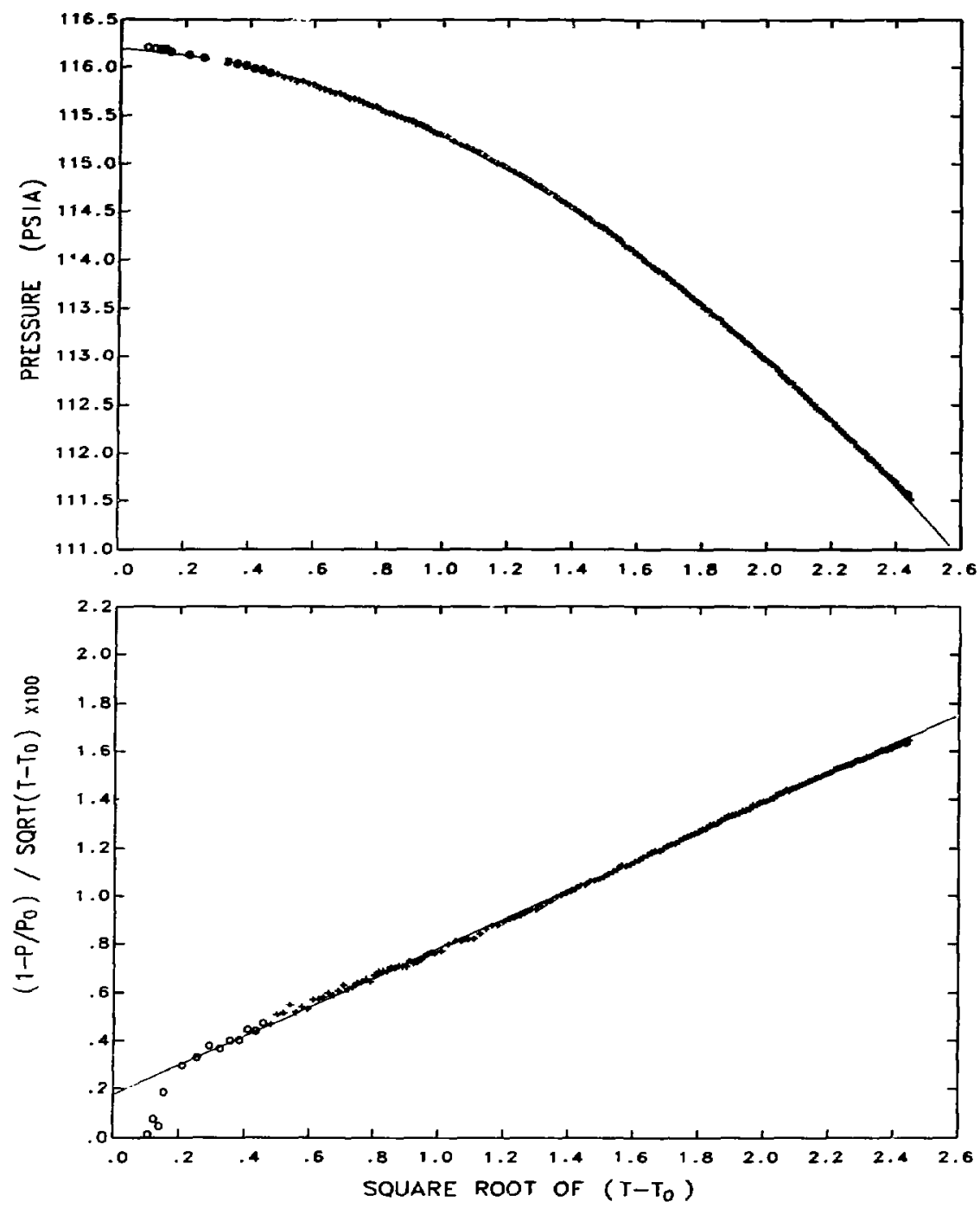

FIGURE B-18. PERMEABILITY TEST S, HOLE P-01, $T_{0}=180.35$ DAYS, AVERAGE TEMPERATURE $=28.2 \mathrm{C}$, 156 OF 171 DATA POINTS USED, RESIDUAL $=.015$. PERMEABILITY $=1.67 \mathrm{ND}$, POROSITY $=.0001$. 

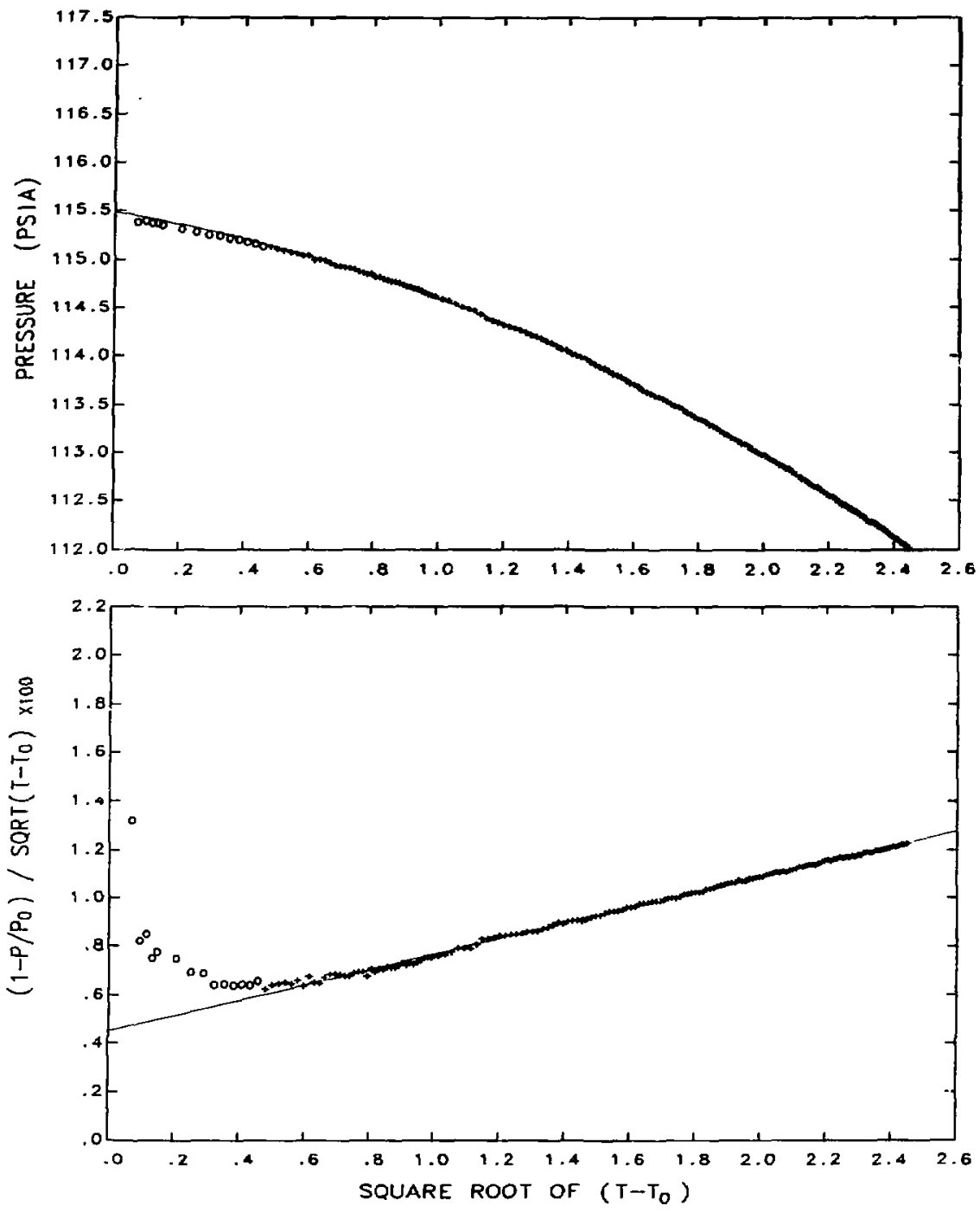

FIGURE B-19. PERMEABILITY TEST S. HOLE I-O6. $T_{0}=180.35$ DAYS, AVERAGE TEMPERATURE $=28.7 \mathrm{C}$. 157 OF 171 DATA POINTS USED, RESIDUAL $=.010$, PERMEABILITY $=.88 \mathrm{ND}$. POROSITY $=.0013$. 

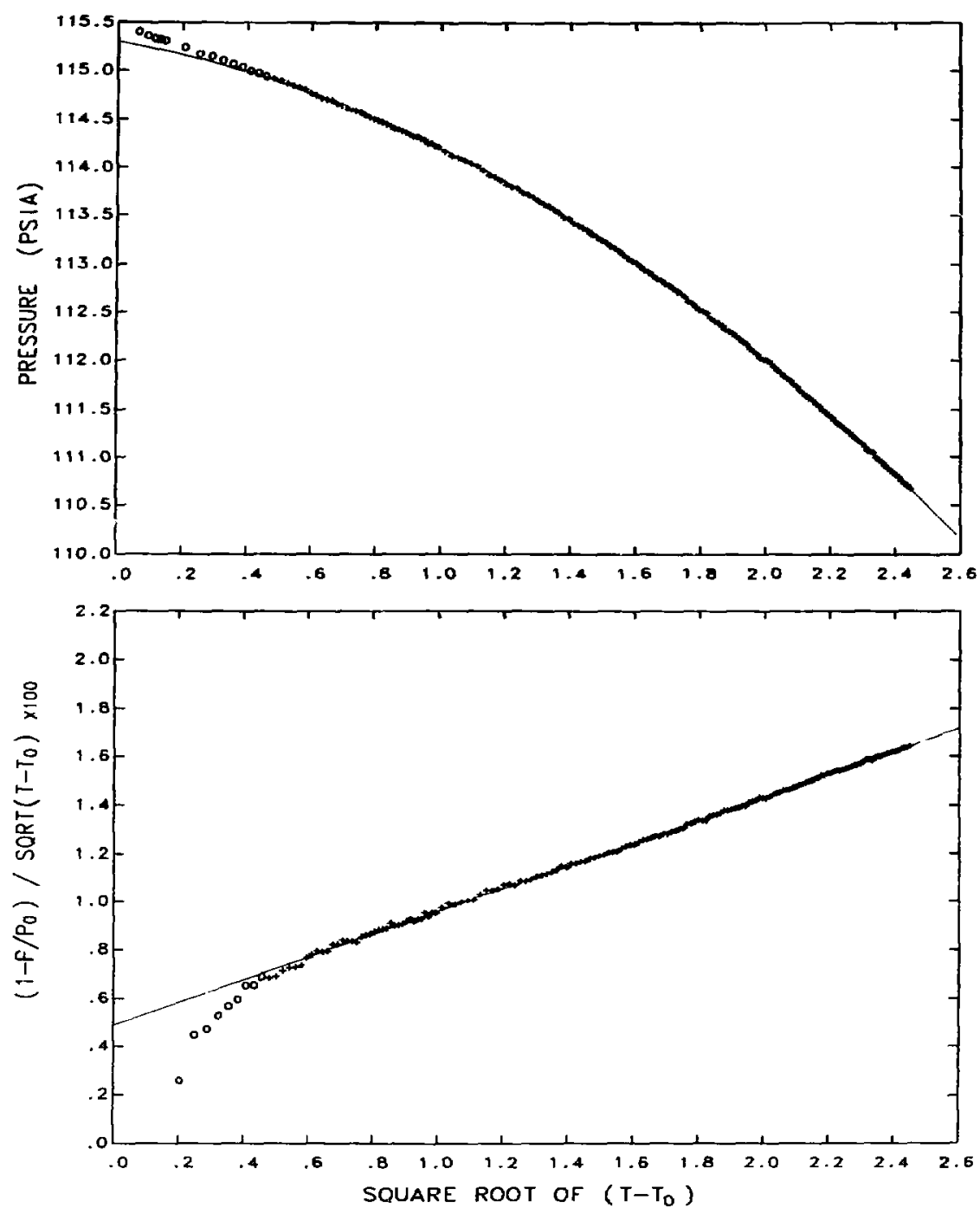

FIGURE B-20. PERMEABILITY TEST $S$, HOLE 1-11, $T_{0}=180.35$ DAYS, AVERAGE TEMPERATURE $=33.7 \mathrm{C}$. 157 OF 171 DATA POINTS USED, RESIDUAL $=.009$. PERMEABILITY $=1.31 \mathrm{ND}$, POROSITY $=.0010$. 